\title{
Animal Research for Alzheimer Disease: Failures of Science and Ethics
}

\author{
John J. Pippin \\ Physicians Committee for Responsible Medicine, Washington, DC, \\ United States \\ jpippin@pcrm.org
}

Sarah E. Cavanaugh

Rockville, Maryland, United States

Francesca Pistollato

European Commission, Joint Research Centre, Ispra, Italy

This is a uniquely human disease, with impairments in abstract reasoning and judgment. We've cured mice engineered with this disease over 500 times. The mouse models don't translate into humans. We know for a fact that mice don't write books.

HoWARD FILLIT, Chief Science Officer, Alzheimer's Drug Discovery Foundation, in Shakoor et al., 2017

Perhaps the most impactful and foreboding development in chronic diseases in recent decades has been the increasing prevalence and awareness of dementia. The various dementias, especially Alzheimer disease (AD), have derailed and ended the lives of tens of millions in America and worldwide. It is a truism that AD patients die twice. First the mind dies, and only later does the body. AD uniquely and unremittingly affects not only patients, but their families, caregivers, and communities. In recent years, AD may have displaced cancer as the most feared disease among Americans. As with other diseases that have no meaningful methods for prevention and treatment, research targeting AD has primarily focused on preclinical approaches, predominantly using animals. Nonetheless, decades of animal research have failed to translate into significant advances in the prevention or treatment of AD. In view of this failure, a different and human-relevant approach is critically needed. 
This chapter addresses the epidemiology and current understanding of AD as a scientific and societal challenge, reviews the uses and results of animal research in basic science and drug development, and discusses risk factors and funding. Important follow-up topics, including current and in-development, human-relevant approaches for replacement of the failed animal research paradigm, deserve comparable treatment and hence are not addressed here. The reader is referred to the list of recommended readings at the end of the chapter for further discussion of these topics.

The ethics of continued use of the animal-based approach in AD is troublesome in at least two respects. First, regardless of where one stands on the ethical spectrum of animal use for medical research, certainly the inhumane and lethal use of animals for demonstrably faulty research is unethical. Second, the ethical responsibility to AD patients, their families, and the larger community demands reliable and useful results, which in turn demand a revised research approach, emphasizing human-relevant methods.

\section{Epidemiology and Current Status}

Dementia can be defined as a disorder of mental capabilities caused by brain disease or injury and marked by memory disorders, impaired thought and reasoning, diminished judgment, social withdrawal, and altered personality. Except for several reversible causes, dementia is a chronic and unremitting disease with a fatal outcome. AD is the most common form of dementia, accounting for $60 \%-80 \%$ of all dementia diagnoses in the United States (US) (Alzheimer's Association, 2017). The next four most prevalent categories of dementia (vascular dementia, dementia with Lewy bodies, frontotemporal dementia, and mixed dementia) account for all but a small percentage of the other diagnoses. Vascular and mixed dementia overlap considerably with AD; nearly all cases of vascular dementia display characteristics of AD (Thal, Grinberg and Attems, 2012), and prevalence figures do not include the AD precursor, mild cognitive impairment (MCI), making the percentage of dementia and incipient dementia attributable to AD even higher (Lopez et al., 2012; Mitchell and Shiri-Feshki, 2009; Roberts et al., 2014a; Ward et al., 2013). AD prevalence increases with age and varies based on diagnostic criteria and death records. It can only be definitively diagnosed by postmortem examination of the brain, though recent advances in neuroimaging and cerebrospinal fluid analysis offer strong clinical evidence and presumptive diagnosis. AD is almost certainly underdiagnosed and underreported, both among persons who die of $\mathrm{AD}$ and 
those who die with AD (James et al., 2014; Taylor et al., 2017; Wachterman, Kiely and Mitchell, 2008; Weuve et al., 2014).

A reasonable estimate of AD prevalence in the Us is $3 \%$ of persons aged $65^{-74}$ years, $17 \%$ of persons aged $75^{-84}$ years, and $32 \%$ of persons aged 85 years and older (Hebert et al., 2013), though some sources estimate the risk for persons 85 years and older as nearly 50\% (Alzheimer's Association, 2012; Chai, 2007; Gatz et al., 2006). About 5.5 million Americans (two-thirds of whom are women) currently have $\mathrm{AD}$, and this number is expected to increase to nearly 14 million by 2050 (Hebert et al., 2013). The number of people living with dementia worldwide is estimated at 47.5 million and is projected to increase to 75.6 million by 2030 and more than triple by 2050 (World Health Organization, 2015). The estimated global cost of AD in 2015 was Us $\$ 818$ billion (McDade and Bateman, 2017), which according to the International Monetary Fund (2017) and the World Bank (2017), would rank as the 18th highest national gross domestic product worldwide.

Conversely, evidence has emerged in recent years suggesting that the incidence and prevalence of $\mathrm{AD}$ and other less common dementias have been decreasing in some populations, perhaps for more than three decades (Langa et al., 2017; Satizabal et al., 2016). Improved risk factor management has been suggested as mitigating AD incidence and prevalence. However, a recent report from the us Centers for Disease Control and Prevention, using state- and county-level death certificate data from the National Vital Statistics System for the period 1999-2014, demonstrates that the AD death rate increased by 54\% between 1999 and 2014 (Taylor et al., 2017). Between 2000-2014, the annualized number of deaths from AD in the us increased by a remarkable $89 \%$ (Alzheimer's Association, 2017); while deaths from heart disease, stroke, and HIV decreased by $14 \%, 21 \%$, and $54 \%$, respectively (Shakoor et al., 2017). The reported increases in $\mathrm{AD}$ deaths and death rate are likely partly attributable to more careful reporting of the disease.

$\mathrm{AD}$ is the sixth leading cause of death in the Us, the fifth leading cause of death for persons 65 years old and older, and among the leading causes of disability and chronic poor health. Among the ten most common causes of death, $\mathrm{AD}$ is the only one with no effective approach for prevention, slowing disease progression, or cure. AD ranked 25th among diseases in the Us, in terms of disability-adjusted life-years lost in 1990 and 12th in 2010, the largest change among the 30 leading diseases (Us Burden of Disease Collaborators, 2013). It is not surprising that the public's fear of AD is escalating. In 2012, a Marist poll of 1,247 US adults found that AD was the most feared disease, chosen by $44 \%$ of participants compared to $33 \%$ for cancer, the second most feared disease (Help for Alzheimer's Families, 2012). 
Most basic science research of AD has used animals, predominantly mice (transgenic, inbred, and wild-type), but also rats and, to a lesser degree, other species, such as rabbits, dogs, and non-human primates. Numerous genetic mutations have been suggested to contribute to the pathological changes in the brains of AD patients, resulting in the selective breeding and research utilization of many transgenic strains of mice and rats expressing those mutations (Cavanaugh, Pippin and Barnard, 2014; Do Carmo and Cuello, 2013; Jackson Laboratory, 2017; Webster et al., 2014). Because gene-disease links have been associated predominantly with autosomal dominant, early-onset familial AD (accounting for fewer than $5 \%$ of cases), transgenic animal models have been based on early-onset disease; and the resultant data have been extrapolated to relate to the much more common, late-onset sporadic AD. Researchers thus seek to recapitulate the genetic and pathological elements of human $\mathrm{AD}$, thereby deriving mechanistic and therapeutic knowledge that is hoped to translate to the human condition.

The business of breeding transgenic animal strains for $\mathrm{AD}$ research has flourished, and there are several commercial sources for these animals (Alzforum, 2017; Charles River, 2017; Jackson Laboratory, 2017; Taconic Biosciences, 2017). Extensive lists of animal models for AD basic science research and drug development have been published, including information on specific genetic configurations and how these animals have been used (Cavanaugh, Pippin and Barnard, 2014; Kumar et al., 2016; Neha et al., 2014; Puzzo et al., 2014).

Because postmortem studies have identified specific brain pathologies among AD patients, most notably extracellular beta-amyloid (Aß) plaques and intracellular neurofibrillary tangles (NFT), the great majority of basic science research has used genetically modified animals to produce similar brain pathologies. Aß plaques have been associated with localized inflammation, contributing to the neuronal and synaptic network damage believed to be related to AD symptoms and disease progression (Eikelenboom et al., 1989; Eikelenboom and Veerhuis, 1996; Rosenberg, 2005; Veerhuis, 2011). The ability to produce $A ß$ plaques and NFT in animal models has been available for more than three decades (Glenner and Wong, 1984; Kosik, Joachim and Selkoe, 1986; Wood et al., 1986). Aß plaques are also formed, then often broken down and removed in healthy human brains; but they persist and accumulate in AD brains. Further complicating the relationship between $\mathrm{A} ß$ plaques and $\mathrm{AD}$, studies have shown that $14 \%-21 \%$ of clinically diagnosed patients have zero or minimal brain Aß plaques on postmortem examination (Beach et al., 2012; Beekly et al., 2007; Serrano-Pozo et al., 2014). 
Tau proteins serve an essential role in the structure and function of microtubules that regulate intracellular transport of important nutrients. NFT consist of hyperphosphorylated tau proteins, resulting in characteristic fibrillar structures and microtubule dysfunction, contributing to neuronal destruction as well as disruption of axonal growth and plasticity (Kosik, Joachim and Selkoe, 1986; Wood et al., 1986). Both extracellular Aß and intracellular NFT are believed to extend damage to the brain's connecting network of dendrites and axons, thereby disrupting intercellular communication and contributing to loss of neurons and neuronal networks. The postulated causative role for $A ß$ and NFT in clinical AD is further confounded by findings that both pathologies have been identified in the brains of patients with frontotemporal dementia, Parkinson disease, Huntington disease, Down syndrome, and amyotrophic lateral sclerosis, as well as in normal brains (Cavanaugh, Pippin and Barnard, 2014; Masters et al., 1985; Ross and Poirier, 2004).

Mutations in genes encoding amyloid precursor protein (APP), as well as the gamma secretase catalytic proteins presenilin 1 (PSEN1) and presenilin 2 (PSEN2), have also been linked to familial AD and have been employed in the study of the disease in animals (Borchelt, et al., 1997; Chartier-Harlin et al., 1991; Goate et al., 1991; Levy-Lehad et al., 1995; Mullan et al., 1992). Inheritance of the apolipoprotein E type 4 allele (ApoE4) has been linked to an increased risk for late-onset $\mathrm{AD}$, though the gene-disease link is weakened by the fact that the ApoE4 allele is neither necessary nor sufficient to predict AD (Corder et al., 1993; Rossor et al., 1996; Sadigh-Eteghad et al., 2012; Strittmatter et al., 1993). Numerous transgenic or double-transgenic animal models have induced and accelerated the development of $A ß$ plaques and have produced associated brain inflammation with cognitive and behavioral pathologies. These models have not produced NFT, but NFT have been produced in conjunction with cognitive deficits by animal models expressing mutated tau protein. A triple transgenic mouse model expressing mutated human Aß precursor protein, $\mathrm{PSEN} 1$, and tau protein was developed to generate both Aß plaques and NFT; this model also produced associated gliosis, synaptic pathology, and impaired memory (Oddo et al., 2003).

The senescence-accelerated mouse prone 8 (SAMP8) strain with a mean lifespan of 9.7 months is considered by researchers to be more suitable to investigate late-onset AD (Pallàs, 2012). SAMP8 mice exhibit dendritic spine loss, spongiosis, gliosis, and forebrain cholinergic deficits, while developing $A \beta$ deposits and aberrant hyperphosphorylated tau-like NFTs (Cheng, Zhou and Zhang, 2014). Despite extensive characterization of SAMP and the SAMP8-APP/PSEN1 mouse model (i.e., double transgenic for amyloid precursor protein and PSEN1 in the senescence-accelerated background of SAMP8) (Lok et al., 2013; Porquet et al., 2015), the genes responsible for senescence and the observed pathological traits are largely unknown. Moreover, 
SAMP8-APP/PS1 mice exhibit significant differences in A $\beta$ plaque formation and cognitive abnormalities when compared with human AD (Porquet et al., 2015).

Further information, regarding the specific animal models, their phenotypic results, and their contributions to the knowledge base for animal surrogates of human AD and some important biological and outcome differences, is available (e.g., Cavanaugh, Pippin and Barnard, 2014; Esquerda-Canals et al., 2017; Geerts, 2009; Kumar et al., 2016).

Many of the animal experiments have been successful in determining the pathogenesis and progression of simulated AD-like disorders at the molecular, cellular, and behavioral levels for the transgenic species studied. Some topics, such as steps in amyloid and tau pathways, have prospered from transgenic animal studies. However, though various transgenic models develop specific phenotypical aspects of $\mathrm{AD}$ - not only $\mathrm{A} ß$ plaques and NFT, but also related gliosis, synaptic alterations, neurodegeneration, behavioral changes, and memory deficit-no individual animal model or combination of models replicates the clinicopathological complexity of human Alzheimer or translates to improved outcomes for Alzheimer patients (Dodart et al., 2002; Duyckaerts, Potier and Delatour, 2008).

What are the correlations between the extensive animal-derived knowledge and the etiology, risk factors, clinical course, pathophysiology, treatments, and outcomes of $\mathrm{AD}$, and what is the payoff expected from basic science research? It is now well understood that, despite the plethora of Alzheimer animal models in use, the interspecies translation is poor for genetic, physiological, and technical reasons (Neha et al., 2014). No matter how close two species, or even two strains within a species, may be genetically, there are immutable differences in gene function, gene expression, protein production, and phenotypic or physiological results that render translation unpredictable and unreliable. Description and explanation of many animal-human discrepancies specific to AD are available (see Cavanaugh, Pippin and Barnard, 2014; Langley, 2014). The demonstrated inability to modify animal models to improve translation provides further evidence that only a shift to human-derived and, thus human-relevant, research methods can improve the applicability of basic science research to human AD.

\section{$4 \quad$ Animal Drug Development Research and Outcomes}

The translational goal of basic science research for medical diseases is to provide the knowledge required to predict, prevent, identify, treat, and hopefully cure these diseases. As such, the success of this approach for AD can be 
measured, in substantial part, by assessing the role of animal research in pharmaceutical development. Over the past three decades, basic and applied science research have identified mechanisms leading to the discovery of drug targets and the development of drugs customized for those targets. An extensive review of these targets, drugs, and clinical trial results is beyond the scope of this chapter but may be found elsewhere (see Berk and Sabbagh, 2013; Cavanaugh, Pippin and Barnard, 2014; Langley, 2014; Schneider et al., 2014).

Though the current discussion is limited to $\mathrm{AD}$, context is also important in fairly assessing the success of preclinical animal research for drug development. For the past eight decades, preclinical testing methods for the safety and efficacy of drugs have relied heavily on the use of animals, not least because this has been the default approach of the us Food and Drug Administration (FDA) and regulatory agencies in most other regions of the world. This animal-testing paradigm has never been subjected to a systematic validation of translation to human medicine or consistency among or within non-human species and different laboratories. Former FDA pharmacology and toxicology reviewer, Anita O'Connor, confirmed this situation in 1998, stating that: "Most of the animal tests we accept have never been validated. They evolved over the past 20 years, and the FDA is comfortable with them." Similarly, in the United Kingdom, Parliamentary Under-Secretary of State, Caroline Flint stated, in 2004, that: "The Home Office has not commissioned or evaluated any formal research on the efficacy of animal experiments" (UK Parliament, 2004). This situation persists not only in these two nations.

As far back as 2003, the FDA reported a clinical trial failure rate of $92 \%$ for drugs deemed safe and effective based on preclinical animal studies, a marked increase from the already high $86 \%$ attrition rate in 1985 , despite purported advances in preclinical drug testing (FDA, 2004; Mitka, 2006; Singh and Henske, 2003). The most recent phase-specific data for drugs tested safe and effective in preclinical animal studies identified clinical trial attrition rates of $56 \%$ for Phase I (designed to assess drug safety and estimate dosing); $82 \%$ for Phase II (designed to assess proof of concept); and $50 \%$ for Phase III (designed to assess safety and effectiveness for humans) (Arrowsmith, 2011a; Arrowsmith, 2011b; Lovell-Badge, 2013) - a cumulative $96 \%$ failure rate. When drug withdrawals, duplicative "me too" drugs, and low patient response rates are included, only about one in one hundred drugs that are tested successfully in animals becomes a unique, effective, and safe medication; and then it is very likely to be effective for only a minority of patients and often marginally so. This is certainly the case with the four drugs licensed to treat AD.

There could hardly be stronger evidence that animal use for drug testing is very unreliable and poorly contributes to drug efficacy or safety in the real world. Added to this serious false-positive problem are the missed opportunities 
for useful drugs, due to false-negative animal testing and adverse effects that would not translate to humans. The cause-effect relationship between animal testing and clinical trial results was succinctly stated by Stanford's Joseph Garner (Garner, 2014, p. 440):

The logic tying failures in clinical trials to basic research in animals is seductively straightforward. Every drug entering human trials, by definition, "worked" in an animal model in terms of both safety and efficacy, and efficacy is the primary reason drugs fail in human trials. Thus, the primary reason for these failures can be traced back directly to false positives in animal models committing the pipeline to develop a drug that will ultimately fail. Straightforward data can be used to make this case. For instance, as reviewed by Zahs and Ashe (2010), over 200 different interventions have been reported to be effective in the APP mouse model of Alzheimer's disease, yet none has proven effective in human trials.

Animal research addressing drug development for $\mathrm{AD}$ is even worse than the overall pattern described above. Despite the 2,204 AD clinical trials (including 1,329 completed, terminated, suspended, and withdrawn drug studies) listed at ClinicalTrials.com on July 24, 2017, only four drugs are currently FDA-approved for treatment of the disease alone or in combination (Table 20.1). Three of these are acetylcholinesterase inhibitors (AChEI), which inhibit the depletion of the crucial neurotransmitter acetylcholine in AD. The fourth drug is a Nmethyl-D-aspartate (NMDA) receptor antagonist that inhibits the destructive excitatory action of glutamate at the cellular level.

It is perhaps a measure of the dearth of therapies to address AD that the FDA has approved even these few drugs, which only scratch the surface of AD therapy. The drugs produce very small changes, of dubious clinical relevance, on cognitive and behavioral measurement scales (Delrieu et al., 2011); they typically have mild impact on symptoms in only a minority of patients, have no effect on disease progression or mortality, often lose any effectiveness within several months, and may produce serious adverse effects.

Despite the low bar for FDA approval of AD drugs, the pharmaceutical industry trade group, Pharmaceutical Research and Manufacturers of America (PhRMA), reported that between 1998-2014, 123 drugs failed in AD clinical trials (2015), further supporting the organization's comments in its 2012 report: "The limited utility of current models of the human disease is a huge barrier in preclinical testing of drug candidates [....] Unfortunately, these medical treatments do not always work, they cannot cure the disease or stop its progression, and when they work their efficacy often wears off over time" (PhRMA, 2012). 
TABLE 20.1 FDA-approved drugs for Alzheimer disease (2019)

\begin{tabular}{|c|c|c|c|c|c|}
\hline Drug name & Brand name & Category & $\begin{array}{l}\text { FDA } \\
\text { approval }\end{array}$ & $\begin{array}{l}\text { Approved } \\
\text { disease stages }\end{array}$ & $\begin{array}{l}\text { Approved } \\
\text { generic }\end{array}$ \\
\hline Donepezil & Aricept & AChEI ${ }^{a}$ & 1996 & All stages & Yes \\
\hline Rivastigmine & Exelon & AChEI & 2000 & $\begin{array}{l}\text { Mild-moderate } \\
\text { Moderate-severe }^{b}\end{array}$ & Yes \\
\hline Galantamine & Razadyne & AChEI & 2001 & Mild-moderate & Yes \\
\hline Memantine & Namenda & NMDARI $^{c}$ & 2003 & Moderate-severe & Yes \\
\hline $\begin{array}{l}\text { Donepezil + } \\
\text { memantine }\end{array}$ & Namzaric & $\begin{array}{l}\text { AChEI + } \\
\text { NMDARI }\end{array}$ & 2014 & Moderate-severe & Yes \\
\hline
\end{tabular}

a Acetylcholinesterase inhibitor

b Patch is approved for moderate-severe

c N-methyl-D-aspartate receptor inhibitor.

The AChEI tacrine was approved for mild-moderate AD in 1993 and withdrawn in 2013 due to severe toxicities

Cummings, Morstorf and Zhong (2014) reported on all registered AD drug trials for the period between 2002-2012, using NIH's ClinicalTrials.gov database to extract drug and trial data. They found that during this period, 244 candidate AD drugs were tested in 413 clinical drug trials. There was a $72 \%$ attrition rate for Phase I trials, which reached $92 \%$ when Phase II trials were added. Only one drug succeeded in Phase III to achieve FDA approval (memantine in 2003). The failure rate was $99.6 \%$ (243 of 244 the drugs tested). An analysis of AD clinical drug trials reported from January 1, 2004 (after memantine approval) through to July 19, 2017, reveals 1,273 completed or closed trials and no approved drugs (ClinicalTrials.gov, n.d.).

PhRMA reported 77 AD drugs in clinical trials in 2016, 21 of which were in Phase III studies (PhRMA, 2016). By May 2017, nine of these drugs had already failed at least one late-stage trial, none had a successful outcome, and numerous others no longer had trials registered on ClinicalTrials.gov. In January 2016. ClinicalTrials.gov listed 93 agents in 115 open AD trials: 24 agents in 36 Phase III trials, 45 agents in $5^{2}$ Phase II trials, and 24 agents in 27 Phase I trials (Cummings, Morstorf and Lee, 2016). In July 2017, none of these had achieved a successful outcome. Data from the July 2017 Alzheimer's Association International Conference reported 58 Phase II and 32 Phase III AD drugs in development, including 8 Phase II and 27 Phase III drugs expected to launch in the next five years (Henriques, 2017; Us Against Alzheimer's, 2017).

Table 20.2 displays notable drugs that have failed late-stage clinical trials in the past six years. Some drugs have failed several clinical trials and some have 
continued to be evaluated in additional late-stage clinical trials. Among drug candidates currently in Phase III trials are Aß antibodies aducanumab (Biogen) and crenezumab (Hoffmann-La Roche); BACE1 inhibitors elenbecestat (Biogen) and JNJ-54861911 (Janssen); 5-HT6 antagonist SUVN-502 (Suven Life Sciences); and NMDA receptor antagonist AVP-786 (Avanir).

Cumulatively, Cummings et al.'s (2014) results from 2002-2012 data and results for 2013-2018, shown in Table 20.2, demonstrate that at least 265 $\mathrm{AD}$ drugs have failed in clinical trials in the past 15 years. The race between translatable research and burgeoning disease is being lost, with no clear path

TABLE 20.2 Notable Alzheimer drug failures from 2013-2018

\begin{tabular}{|c|c|c|c|c|}
\hline Failed drug & Category & Sponsor & $\begin{array}{l}\text { Most recent } \\
\text { failed trial }\end{array}$ & Reason for failure \\
\hline LY 2886721 & BACE 1 inhibitor & Lilly & 2013 & Toxicity \\
\hline Intravenous Ig & Immune modulator & Baxter, Intl. & 2013 & Ineffective \\
\hline Begacestat & $\gamma$ secretase inhibitor & $\begin{array}{l}\text { Bristol-Myers } \\
\text { Squibb }\end{array}$ & 2013 & Ineffective \\
\hline Bapineuzumab & $A ß$ antibody & Pfizer & 2014 & Ineffective \\
\hline Affitope ADo2 & $A ß$ vaccine & AFFiRiS AG & 2014 & Ineffective \\
\hline PFo4447943 & PDE9A inhibitor & Pfizer & 2014 & Ineffective \\
\hline Gantenerumab & $A ß$ antibody & $\begin{array}{l}\text { Hoffmann-La } \\
\text { Roche }\end{array}$ & $\begin{array}{l}2014 \\
2015\end{array}$ & $\begin{array}{l}\text { Ineffective } \\
\text { Toxicity }\end{array}$ \\
\hline BI 1181181 & $\mathrm{BACE} 1 / 2$ inhibitor & $\begin{array}{l}\text { Boehringer } \\
\text { Ingelheim }\end{array}$ & 2015 & \\
\hline$\omega-3$ fatty acid & Dietary supplement & $\begin{array}{l}\text { University } \\
\text { Hospital, Toulouse, } \\
\text { France }\end{array}$ & 2015 & Ineffective \\
\hline Sembragiline & MAO-B inhibitor & Roche & 2015 & Ineffective \\
\hline Encenicline & $\alpha_{7}$ NAR agonist & FORUM & 2015 & $\begin{array}{l}\text { Toxicity(FDA } \\
\text { halted) }\end{array}$ \\
\hline Masitinib & $\begin{array}{l}\text { Tyrosine kinase } \\
\text { inhibitor } \\
\text { Aß vaccine }\end{array}$ & AB Science & 2015 & Ineffective \\
\hline CAD 106 & & Novartis & 2016 & Ineffective \\
\hline Idalopirdine & 5-HT6 antagonist & $\begin{array}{l}\text { Lundbeck \& } \\
\text { Otsuka }\end{array}$ & 2016 & Ineffective \\
\hline PFo5212377 & 5-HT6 antagonist & Pfizer & 2016 & Ineffective \\
\hline Bexarotene & Anti-neoplastic & Cleveland Clinic & 2016 & Ineffective \\
\hline
\end{tabular}


TABLE 20.2 Notable Alzheimer drug failures from 2013-2018 (cont.)

\begin{tabular}{lllll}
\hline Failed drug & Category & Sponsor & $\begin{array}{l}\text { Most recent } \\
\text { failed trial }\end{array}$ & Reason for failure \\
& & & & \\
LMTX & $\begin{array}{l}\text { Tau aggregation } \\
\text { inhibitor }\end{array}$ & TauRx & 2016 & Ineffective \\
Bryostatin & PKC modulator & Neurotrope & 2017 & Ineffective \\
AC-1204 & Ketosis inducer & Accera & 2017 & Ineffective \\
Intepirdine & 5-HT6 antagonist & Axovant Sciences & 2017 & Ineffective \\
BAN2401 & Aß antibody & Biogen/Eisai & 2017 & Ineffective \\
Solanezumab & Aß antibody & Lilly & 2018 & Ineffective \\
Pioglitazone & antiglycemic & Takeda/Zinfandel & 2018 & Ineffective \\
BI 409306 & PDE9A inhibitor & Boehringer & 2018 & Ineffective \\
Verubecestat & BACE1 inhibitor & Merck & 2018 & Ineffective \\
Azeliragon & RAGE inhibitor & vTv & 2018 & Ineffective \\
Pimavanserin & 5-HT2A antagonist & Acadia & 2018 & Ineffective \\
Atabecestat & BACE1 inhibitor & Johnson \& Johnson & 2018 & Toxicity \\
Lanabecestat & BACE1 inhibitor & Lilly & 2018 & Ineffective \\
Elenbecestat & BACE1 inhibitor & Biogen/Eisai & 2018 & Ineffective \\
& & & & \\
\hline
\end{tabular}

BACE1=beta-site amyloid precursor protein-cleaving enzyme 1; Ig=immunoglobulin; RAGE $=$ receptor for advanced glycation endproducts; PDE9A=phosphodiesterase 9A; MAO-B = monoamine oxidase $\mathrm{B} ; \alpha 7 \mathrm{NAR}=\alpha 7$ nicotinic acetylcholine receptor; 5 -HT6=5hydroxytryptamine (serotonin) type 6 receptor; $\mathrm{PKC}=$ protein kinase $\mathrm{C} ; 5^{-} \mathrm{HT} 2 \mathrm{~A}=5^{-}$ hydroxytryptamine (serotonin) type $2 \mathrm{~A}$ receptor.

to improvement other than the replacement of the failed animal research paradigm by a commitment to human-relevant research methods.

\section{$5 \quad$ Whither the Amyloid Cascade Hypothesis?}

The amyloid cascade hypothesis, in its initial description (Hardy and Allsop, 1991; Hardy and Higgins, 1992) and in its reappraisal (Hardy, 2006; Hardy and Selkoe, 2002), has been foundational for AD preclinical and clinical research for a quarter of a century. Early and widespread acceptance of the hypothesis has impacted research gatekeepers, such as funding agencies, journal editors, peer reviewers, and pharmaceutical companies. The amyloid cascade hypothesis, 
derived from human autopsy studies, identifying the presence and presumed causative roles for $A ß$ plaques and tau proteins, proposes that sequential enzymatic cleavage of mutated APP by secretase enzymes results in deposition of soluble $A ß$ protein oligomers that coalesce into plaques, and that downstream events include tau protein and NFT formation and cell death. The specifics of inflammation and destruction of neuronal networks were identified with further investigation. This entire process is termed, neurodegeneration.

In the pursuit of $\mathrm{AD}$ research, abundant information has been obtained casting doubt on the amyloid cascade hypothesis. Paramount among contrary information is the finding that a meaningful percentage of young adult (Baker-Nigh et al., 2015) and older persons (Armstrong et al., 1996; Esparza et al., 2013; Haroutunian et al., 2008; Monsell et al., 2013; Price et al., 2009), without dementia, have substantial $A ß$ plaque deposition demonstrated in brain imaging and postmortem studies. In one large review, amyloid biomarkers increased with age and were present in $10 \%-44 \%$ of cognitively normal participants aged 50-90 years (Jansen, et al., 2015). Lon Schneider of the University of Southern California, Keck School of Medicine, stated that: "There are people who die with a head full of amyloid and have no cognitive impairment whatsoever" (Mullin, 2017). Conversely, Aß plaques may be absent or minimally present in clinically diagnosed AD patients (Monsell et al., 2015; Morris, Clark and Vissel, 2014; Terry et al., 1991). A recent report demonstrates that tau oligomers, produced subsequent to $A ß$ deposition, are also present in the sera of aged normal controls as well as AD patients (Kolarova et al., 2017). It has been reported that some degree of tau pathology is ubiquitous in postmortem human brains (Braak and Braak, 1997; Braak and Del Tredici, 2011).

Since some drugs have successfully removed brain $A ß$ plaque without producing improvement in cognition and other symptoms and without improving clinical course or mortality, it has been proposed that $A ß$ plaques may not be causative for $\mathrm{AD}$. Tau pathology not only is triggered by $\mathrm{A} ß$ plaques but also appears to progress unabated even after the removal of $A ß$ plaques, suggesting that therapies targeting Aß are unlikely to succeed in controlling AD (Hampel et al., 2010; Wang et al., 2016). Some recent basic science and drug development research has focused on a possible AD causative role for tau proteins rather than $A ß$ plaques, but the only completed tau-targeting Phase III drug trial (a tau protein aggregation inhibitor known as LMTX, LMTM, or TRxo237) failed to show benefits (Alzforum, 2016a). The true AD target may be the synaptic and neuronal network destruction that is the common final pathway to dementia. An alternative interpretation is that the timing of $A ß$-targeted therapies may be 
key: Once Aß plaque has formed, it may be too late to reverse the pathological consequences.

$\mathrm{AD}$ has appropriately been described as late-life phenotypes, beginning as midlife pathologies with a two-decade or more latency period. There is now a corresponding move towards identifying and validating biomarkers to aid in detecting $\mathrm{AD}$ in its earliest stages, or even before symptoms appear, so that the neuronal network damage may be prevented rather than treated (Donohue et al., 2017; Schneider et al., 2014). Foremost among these approaches may be prevention trials enrolling asymptomatic persons, with characteristic neuroimaging pathology or with specific cerebrospinal fluid biomarkers (Donohue et al., 2017; Jansen et al., 2015; Olsson et al., 2016; Ramachandran, 2016), and targeting subsequent cognitive loss and the development of MCI or AD.

Earlier intervention is a logical approach derived from the failure of later clinical intervention, but its value is debatable for at least three reasons. First, the biomarkers indicating risk for $\mathrm{AD}$ are not yet sufficiently accurate to exclude persons who would never develop AD or even MCI from clinical trials. Second, fewer than half of persons with $\mathrm{MCI}$ will progress to AD, making even this indicator of limited utility and suggesting that earlier biomarkers may be fraught with low specificity and positive predictive value (Mitchell and ShiriFeshki, 2009; Richard and Brayne, 2014; Roberts et al., 2014a; Ward et al., 2013). Third, this approach does not directly address the failure of animal research to identify disease-modifying therapies, though it is postulated that some failed therapies may be effective if applied earlier.

So, the fate of the amyloid cascade hypothesis remains unknown but appears tenuous; and its demise would seriously compromise decades of basic science, clinical, and pharmaceutical efforts. Outcomes to date have not confirmed, and generally do not support, the amyloid cascade hypothesis; and if current and pending early-stage and presymptomatic Aß-targeted studies fail to impact outcomes, it must be presumed to be incorrect. It is axiomatic that the first step in understanding, characterizing, and addressing disease is to determine the cause(s). We have not demonstrably done this for $\mathrm{AD}$, arguably because basic science research, predominantly using transgenic animals, has been unable to accomplish the task despite more than three decades of effort.

Concomitant with the emphasis on earlier detection and preventive measures for $\mathrm{AD}$, there is a need to identify factors that are predictive of, 
contributory to, or protective for the development of cognitive impairment and AD. In particular, modifiable lifestyle factors associated with risk for cognitive impairment and $\mathrm{AD}$ offer a particularly appealing approach to prevention-lifestyle modifications without adding heretofore failed drug treatments.

Blood pressure - pressure variability rather than absolute systolic, diastolic, or mean blood pressure - has been associated with risk for subsequent cognitive decline and $\mathrm{AD}$ in a unique manner. The same pattern of greater cognitive decline with greater blood pressure variability has been established for office (Alpérovitch et al., 2014; Sabayan et al., 2013); ambulatory (McDonald et al., 2017); and home (Matsumoto et al., 2014; Oishi et al., 2017) blood pressure measurements and for day-to-day or month-to-month variability. Though blood pressure variability has also been shown to correlate with cardiovascular event risk and target organ damage (Kikuya et al., 2008; Rothwell et al., 2010); it is unknown whether there are shared mechanisms with cognitive decline, and it is also unknown whether specific blood pressure control efforts impact the cognitive risk (Palatini, 2014). Observational studies of hypertension and cognitive risk have been heterogeneous, but the evidence is strongest for risk correlation between mid-life hypertension and late-life AD and all cause dementia (Kennelly, Lawlor and Kenny, 2009a; Kennelly, Lawlor and Kenny, 2009b; Purnell et al., 2009; Qiu, Winblad and Fratiglioni, 2005), with an estimated relative risk of 1.6 (Barnes and Yaffe, 2011).

Regular exercise is a topic of great interest for potential reduction of the risk for cognitive decline and AD. A prospective study of 200 persons with mild dementia evaluated cognitive outcomes of a group receiving 16 weeks of supervised exercise and a non-exercise control group. No differences were seen in objective measures of cognition, quality of life, or ability to perform activities of daily living (Hoffman et al., 2016). This outcome was confirmed in a Swedish study of 186 persons with dementia who participated in an intensive four-month exercise program (Toots et al., 2017). A Western Australia prospective trial evaluated exercise effect on cognition among 138 at-risk older adults, randomized to either 24 weeks of supervised physical activity or no exercise. This methodologically problematic study showed minimal and dubious improved cognitive measures over 18 months (Lautenschlager et al., 2008). In a secondary analysis of the randomized prospective LIFE trial, a 24-month physical activity intervention involving 1,635 sedentary older adults, no exercise-related improvements were seen in global or domain-specific cognitive function (Sink et al., 2015).

In contrast, a 2009 meta-analysis of 16 studies including 163,797 nondemented participants showed an approximate $45 \%$ reduced risk for AD and $28 \%$ reduction in all-cause dementia, between the highest and lowest physical 
activity groups, with a relative risk among inactives of 1.82 for $\mathrm{AD}$ (Hamer and Chida, 2009). Another systematic review reported that physical inactivity was linked to an increased risk for cognitive impairment in 20 of 24 included studies (Rolland, Abellan van Kan and Vellas, 2008). A 2010 meta-analysis of 15 prospective studies, including 33,816 nondemented subjects, who were followed for 1 to 12 years, showed a decreased risk for subsequent cognitive decline at all exercise levels (Sofi et al., 2010). These meta-analysis findings were compromised by conflicting results and methodological heterogeneity among the studies reviewed. A secondary analysis of a 30-year questionnaire-based study of midlife exercise found no relationship to subsequent cognitive impairment or dementia (Gross et al., 2017).

The majority of studies evaluating exercise or uncharacterized physical activity as predictors of subsequent cognitive impairment, $\mathrm{AD}$, or all-cause dementia are observational cohort studies, variably compromised by methodological limitations. These limitations include poorly characterized or unsupervised exercise, inconsistent exercise and activity patterns, self-reporting by subjects, questionnaire-based data collection (subject to recall bias), researcher bias, variable influence of the observers on participant performance, and short interventional and observational periods, among other disadvantages. Cumulative findings to date show no significant evidence for exercise benefit regarding progression among persons with dementia, and conflicting evidence for benefit regarding future development of cognitive decline, AD, or all-cause dementia.

The relationship of diet to risk for cognitive decline and $\mathrm{AD}$ or uncharacterized dementia is a revealing area of investigation. Studies of specific dietary supplements have predominantly failed to show decreased risks for prevalent or incident cognitive decline and dementia, excluding replacement therapy for severe nutritional deficiencies, such as vitamin $B_{12}$ and niacin. Dietary supplement animal research supports beneficial effects for vitamins $\mathrm{C}$, D, and $\mathrm{E}$ (Anastasiou, Yannakoulia and Scarmeas, 2014; Guerrero et al., 1999; Joseph et al., 1998; Socci, Crandall and Arendash, 1995; Yamada et al., 1999). Human studies of dietary vitamin intake have shown inconsistent results. Prospective observational studies in Chicago (Morris et al., 2002) and Rotterdam (Engelhart et al., 2002) showed lower AD risk with greater dietary vitamin $\mathrm{E}$ intake, while a similar study in New York showed no association (Luchsinger et al., 2003). The Rotterdam study showed lower AD risk with greater vitamin C intake, but the other two studies did not. The Chicago study also found a worrisome positive correlation between vitamin $\mathrm{C}$ intake and the risks for hypertension and stroke. None of the three studies showed benefit from vitamin $\mathrm{C}$ or vitamin $\mathrm{E}$ supplements. 
In a 2014 study of elderly hospitalized patients, blood levels of 25-hydroxy vitamin D did not discriminate among cognitively normal (200); MCI (46); and demented (182) patients, nor did the levels predict conversion to dementia (Graf et al., 2014). Conversely, another observational study showed a relative risk for incident $\mathrm{AD}$ of 1.69 for deficient and 2.22 for severely deficient vitamin D levels among 1,658 healthy ambulatory adults (Littlejohns et al., 2014). Overall, human vitamin D study outcomes have been heterogeneous, but the highest quality evidence (clinical trials) does not support vitamin D-related benefit (Anastasiou, Yannakoulia and Scarmeas, 2014).

Dietary saturated fat and trans fat intake have been associated with higher AD risks in human studies (Kalmijn et al., 1997; Luchsinger et al., 2002; Morris et al., 2003), though this correlation disappeared during follow-up in one study (Kalmijn et al., 1997). A more recent systematic review revealed mixed evidence among four observational studies of saturated fat and trans fat intake and MCI or dementia (Barnard, Bunner and Agarwal, 2014). A study of 444 Finnish men linked elevated midlife blood cholesterol with increased subsequent AD risk (Notkola et al., 1998). Observational studies have reported lower AD risk with statin therapy (Jick et al., 2000; Wolozin et al., 2000); but a 2016 Cochrane review found no benefit on five cognitive tests in two randomized placebo-controlled trials of statins, including 26,340 participants (McGuinness, et al., 2016). Diets consisting substantially of meat, dairy, processed and fatty foods, snack foods (often high in trans fats), and high caloric content contribute to known AD risk factors as well as other health risks.

The pattern of accelerated $\mathrm{AD}$ and all-cause dementia after adoption of the American-style diet is widely evident, including in Japan (Grant, 2014), China (Chan et al., 2013), rural India (Chandra, et al., 1998), eight developing nations (Grant, 2014), and among participants in the Adventist Health Study (Giem, Beeson and Fraser, 1993). A recent comprehensive review of dietary data and cognitive risks from 2014-2016 presented updated data regarding seafood intake and lines of evidence against cognitive protection, despite the purported favorable effects of the omega-3 fatty acids, eicosapentaenoic acid, and docosahexaenoic acid (Solfrizzi et al., 2017).

Type 2 diabetes mellitus ( $\mathrm{T} 2 \mathrm{DM})$ is an $\mathrm{AD}$ risk factor, resulting predominantly from the combined and cumulative effects of poor diet, sedentary lifestyle, and obesity. T2DM and AD are known to share pathologies, such as cerebrovascular disease, brain atrophy and diminished brain volume, impaired brain glucose metabolism, and CNS insulin resistance (Asih et al., 2017; Bharadwaj et al., 2017; Sutherland et al., 2017); and both disorders have been linked to tau pathology and neurodegeneration (Sutherland et al., 2017). At the clinical level, $\mathrm{T}_{2} \mathrm{DM}$ and $\mathrm{AD}$ both increase in incidence with age; and risks for 
both have been shown for sedentary lifestyle, hypertension, poor diet, obesity, dyslipidemia, and smoking. Overlapping features, including the role of insulin resistance in the brain, have resulted in the designation of $\mathrm{AD}$ as "type 3 diabetes" (De La Monte and Wands, 2008).

Observational cohort studies, systematic reviews, and meta-analyses have predominantly identified $\mathrm{T}_{2} \mathrm{DM}$ in cognitively normal persons as a risk factor for MCI, AD, and all-cause dementia (Barnes and Yaffe, 2011; Biessels et al., 2006; Biessels et al., 2014; Cheng et al., 2012; Cukierman, Gerstein and Williamson, 2005; Exalto et al., 2012; Gudala et al., 2013; Kopf and Frolich, 2009; Lu, Lin and Kuo, 2009; Roberts, et al., 2014b; Yaffe, et al., 2012; Zhang et al., 2017), though some of these studies have methodological flaws and unaccounted bias (Sutherland et al., 2017). This correlation was not confirmed for the progression of cognitive decline among AD patients (Li et al., 2017). Several investigators have estimated the relative risk for $\mathrm{AD}$ from $\mathrm{T}_{2} \mathrm{DM}$ as 1.5 (Chatterjee et al., 2016; Cheng et al., 2012; Gudala et al., 2013), including recent population-based studies of more than 2.3 million (Chatterjee, et al., 2016) and more than 1.7 million persons (Zhang et al., 2017). A combined systematic review and meta-analysis of eight studies of T2DM and AD risk reported that seven studies found a positive correlation, but only two reached statistical significance, and overall relative risk was 1.4. (Lu, Lin and Kuo, 2009).

The risk for development of MCI, AD, and all-cause dementia increases with T2DM duration (Asih et al., 2017; Bruce et al., 2014). Dementia risk appears to be proportional to diabetes severity (Yaffe, et al., 2012), to occur at a younger age when T2DM is present (Zilkens et al., 2013), and to display shorter survival when combined with T2DM (Helzner et al., 2008; Zilkens et al., 2013). The rapidly increasing worldwide prevalence of $\mathrm{T} 2 \mathrm{DM}$, thus, suggests not only more prevalent AD, but also younger onset and shortened survival for AD patients. Conversely, improved $\mathrm{T}_{2} \mathrm{DM}$ prevention would be expected to have a beneficial effect on AD prevalence, onset, and mortality.

Based on the preceding and similar findings, certain recommendations can be made to minimize modifiable risks for cognitive decline and AD. These recommendations are built on the preponderance of evidence from human studies and the overall beneficial effects for cardiovascular disease, T2DM, obesity, hypertension, and other AD risk factors as well as for the hard endpoints of cognitive decline and dementia. Elements of the lifestyle prescription include, regular exercise or other physical activities; adoption of heart-healthy diets, such as the Mediterranean diet and other plant-based diets emphasizing fruits, vegetables, whole grains, and legumes (with consideration for excluding seafood consumption due to cholesterol content and uncertain benefit); preference for food sources rather than supplement sources of potentially protective dietary components; maintenance of normal body weight, blood 
pressure, blood glucose and lipids; and other factors not discussed here, such as not smoking and attainment of at least a high school level of education. As a bonus, and in contrast to drug therapies, the side effects of this prescription are beneficial.

\section{Brief Overview of Research Funding}

During the first decade of the twenty-first century, AD research funding from NIH was strikingly low, compared to other widespread, lethal, and costly diseases. Passage of the Us National Alzheimer's Project Act (NAPA) by Congress in January 2011, focused greater emphasis on AD research, and federal funding increased slowly until the 2016 and 2017 fiscal years showed large increases. In 2012, NIH research funding for $\mathrm{AD}$ and $\mathrm{AD}$-related dementias was half a billion dollars, compared to US $\$ 1.3$ billion for heart disease, US $\$ 3.1$ billion for HIV/AIDS, and US $\$ 5.6$ billion for cancers. AD research funding did not exceed us $\$ 600$ million until 2015, but it received a $60 \%$ increase in 2016 and a $40 \%$ increase in 2017 (Alzforum, 2016b; Moore, 2017; NIH, 2016). Projected NIH AD research funding for 2017 is nearly us $\$ 1.4$ billion, almost triple the funding of the past five years, while funding for heart disease, HIV/AIDS, and cancers has remained unchanged.

While this is very good news for AD research, the devil is in the details. NIH funding in this area has been heavily weighted towards animal research for at least the past decade, supporting three times as many animal research protocols as human-specific protocols, and spending more than twice as many tax dollars for animal research (Figure 20.1). Total NIH expenditures for AD and AD-related dementia research since 2011 is more than us $\$ 5$ billion, with no clinical return on this investment. If this pattern of dependence on animal research is unchanged, genetic principles, interspecies differences, and history tell us that the AD animal research paradigm will continue to fail in producing advances in AD prevention and treatment, regardless of how much money is directed towards that goal.

Some private funding sources, which collectively distribute tens of millions of dollars annually for AD research, have shown a broader perspective regarding the directions for AD research. For example, in 2016 the Alzheimer's Association partnered with philanthropist Michaela Hoag to announce its Part the Cloud Challenge and grants totalling us $\$ 7$ million to fund clinical trials investigating brain inflammation in AD (Alzheimer's Association, 2016). The Alzheimer's Drug Discovery Foundation (2017) funds many non-amyloid, non-tau research approaches. The Paul G. Allen Family Foundation's us $\$ 7$ million award in 2015 sought innovative AD research approaches, emphasizing the 
A NIH Funded Projects (FY2007-FY2017)

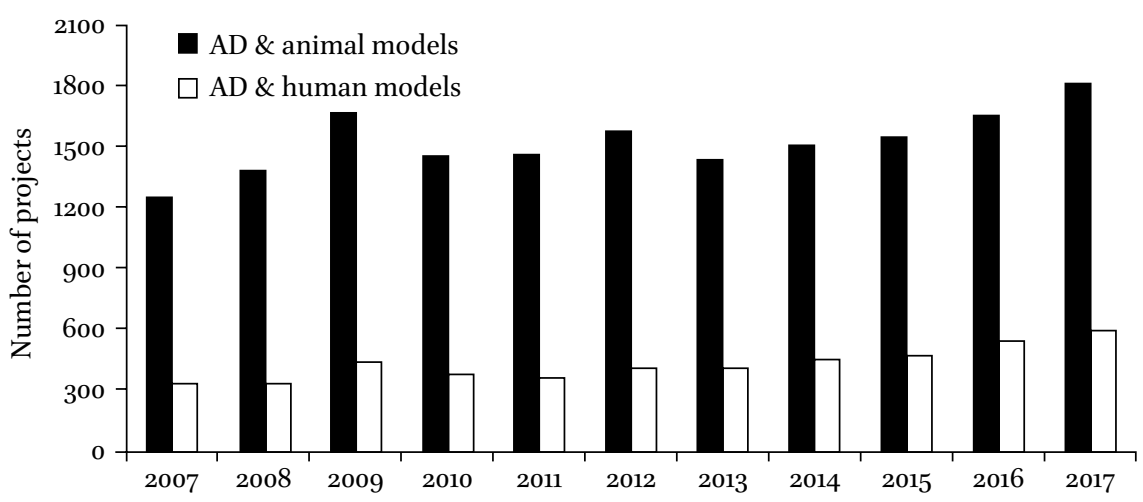

B NIH Funded Projects (FY2007-FY2017)

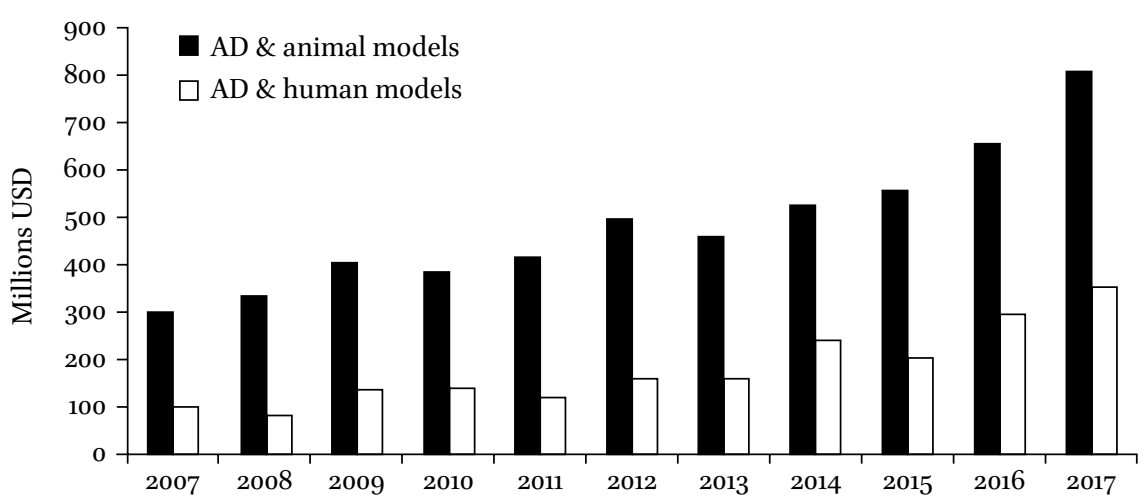

FIGURE 20.1 NIH funding for Alzheimer disease research.

Bar graphs report the absolute numbers of Alzheimer's-related projects focused on the use of animal models (black bars) versus projects accounting only for human-relevant models/methods (white bars). (A) and (B) present relative funding provided by the $\mathrm{NIH}$ from 2007 to 2017. (Updated from Pistollato et al., 2016)

human disease, and the Microsoft cofounder stipulated that at least one member of each of the five recipient research teams must not be an AD researcher (Begley, 2016; Paul G. Allen Philanthropies, 2015). Similarly, the Darrell K. Royal Research (DKR) Fund for Alzheimer's Disease (2016) "is interested in novel, innovative and cutting-edge approaches to Alzheimer's disease, dementia, Traumatic Brain Injury, and related disorders. Additionally, the DKR Fund is particularly interested in non-amyloid and non-tau approaches that may not receive funding through traditional mechanisms. Studies that pilot novel mechanisms and novel therapeutic interventions are particularly encouraged." 
(Underline in original.) It is through innovative and nontraditional research design, specifically human-relevant research, that the inability to translate basic science discoveries to AD prevention, treatment, and successful drug development may be overcome.

\section{Conclusions: The Process and the Ethics}

Perhaps as starkly as for any other disease, AD research ethics must address both animal use and human outcomes. This is because the animals suffer captive breeding and genetic alteration, community disruption, confinement, handling, fear, and painful procedures-and because AD research animals always die. It is also because the human disease is prevalent, frightening, and debilitating and its victims also always die from or with the disease. The animal-use ethical question involves a spectrum of viewpoints, ranging from no concern for the animals to strong objection to any harmful animal use for research purposes. Public surveys over the past few decades have shown a shift towards the latter position or towards restricting animal use to essential and unavoidable circumstances, the definition of which is also variable. But wherever one stands on the animal-use ethical spectrum, hopefully all can agree that the conduct of frightening, painful, and lethal experiments on sentient beings - whether mice, dogs, or monkeys - is unacceptable when the research translates in no significant way to human benefits, despite decades of effort. The authors of this chapter have been animal researchers, and they have firsthand knowledge that the process is unavoidably cruel, painful, unreliable, and ultimately unrewarding. Nonetheless, we have not argued that no useful knowledge ever results from animal experiments, but we have demonstrated that such knowledge is restricted in practical terms to the genetically manipulated experimental species. That is, it is unreliable for human medicine and does not result in meaningful treatments for AD.

In view of the billions of dollars of federal and private research support for AD, now more than one billion dollars annually of taxpayer funds alone, meaningful clinical results are an ethical expectation. Yet, such results remain absent, and there are no current animal research approaches promising translational basic science revelations or improved drug development in the foreseeable future. Spiraling costs related to basic science and clinical research, clinical diagnostics, acute and especially chronic patient care, caregiver support, and the economic consequences facing families, communities, and businesses are on track to decimate federal and private insurance programs and further impair economic productivity. 
Arguably the most immediate ethical question regards accountability to $\mathrm{AD}$ patients, those at risk for $\mathrm{AD}$, their families and communities. The costs of a failed animal research underpinning for $\mathrm{AD}$ are not limited to money spent and strained research resources, and include irretrievable losses in time, hope, and human lives. Of all the ethical accompaniments of AD animal research, the deferred and unrealized obligations to those impacted by $\mathrm{AD}$, the persistence in pursuing a failed research model, the recurring hype surrounding drugs that cannot affect $\mathrm{AD}$ or its outcome, the advances perennially "just around the corner" are the real-world human consequences. As a corollary, preclinical researchers in the field have spent years or decades performing productive bench work without contributing to improving quality of life, delaying disease progression, or prolonging the lives of $\mathrm{AD}$ patients.

For now, and likely years ahead, there will be nothing more than the four largely inconsequential AD drugs currently available. Neurobiologist, George Perry, Dean of the College of Sciences at the University of Texas at San Antonio, summed this up: "The field has known for over 10 years, probably 15 years, that the models were not Alzheimer disease and could not predict therapeutic efficacy" (Begley, 2016). This paralyzing mindset must be overcome to gain ground on $\mathrm{AD}$, and the replacement of animal research with human-relevant research methods is the path forward.

\section{References}

Allen, Paul G. Philanthropies (2015). Foundation Awards $\$ 7$ million to Reveal Biology of Alzheimer's Disease. Press Release. [online] Available at: http://www.pgafamil yfoundation.org/news/news-articles/2015-news-items/adi-alzheimers-press -release [Accessed 18 May 2017].

Alpérovitch, A., M. Blachier, A. Soumaré, K. Ritchie, J-F Dartigues., S. Richard-Harston and C. Tzourio (2014). Blood pressure variability and risk of dementia in an elderly cohort, the Three-City Study. Alzheimer's \& Dementia, 10(5), pp. S330-S337.

Alzforum (2016a). In First Phase 3 Trial, The Tau Drug LMTM Did Not Work. Period. [online] Available at: http://www.alzforum.org/news/conference-coverage/first -phase-3-trial-tau-drug-lmtm-did-not-work-period [Accessed 30 May 2017].

Alzforum (2016b). Proposed 2016 Budget Boosts Alzheimer's Funding by 60 Percent. [online] Available at: http://www.alzforum.org/news/community-news/proposed-2016 -budget-boosts-alzheimers-funding-6o-percent [Accessed 17 May 2017].

Alzforum (2017). Research Models; Alzheimer's Disease. [online] Available at: http:// www.alzforum.org/research-models/alzheimers-disease [Accessed 25 April 2017]. 
Alzheimer's Association (2012). 2012 Alzheimer's Disease Facts and Figures. [online] Available at: https://www.alz.org/downloads/facts_figures_2012.pdf [Accessed 19 April 2017].

Alzheimer's Association (2016). Alzheimer's Association Issues $\$ 7$ million Challenge to Scientists to Speed Drug Discovery. [online] Available at: http://alz.org/documents _custom/ptc_grants_080216.pdf [Accessed 11 May 2017].

Alzheimer's Association (2017). 2017 Alzheimer's Disease Facts and Figures. [online] Available at: http://www.alz.org/dementia/types-of-dementia.asp [Accessed 2 May 2017].

Alzheimer's Drug Discovery Foundation (2017). Research Priorities. [online] Available at: https://www.alzdiscovery.org/research-and-grants/priorities [Accessed 18 May 2017].

Anastasiou, C., M. Yannakoulia and N. Scarmeas (2014). Vitamin D and Cognition: An Update of the Current Evidence. Journal of Alzheimer's Disease, 42 (Supp 3), pp. $\mathrm{S}_{71-S 80 .}$

Armstrong, R., N. Cairns, D. Myers, C. Smith, P. Lantos and M. Rossor (1996). A Comparison of $ß$-amyloid Deposition in the Medial Temporal Lobe in Sporadic Alzheimer's Disease, Down's Syndrome, and Normal Elderly Brains. Neurodegeneration, 5(1), pp. $35^{-41 .}$

Arrowsmith, J. (2011a). Phase II Failures: 2008-2010. Nature Reviews Drug Discovery, 10(5), pp. 328-329.

Arrowsmith, J. (2011b). Phase III and Submission Failures: 2007-2010. Nature Reviews Drug Discovery, 10(2), p. 87 .

Asih, P., M. Tegg, H. Sohrabi, M. Carruthers, S. Gandy, F. Saad, G. Verdile, L. Ittner and R. Martins (2017). Multiple Mechanisms Linking Type 2 Diabetes and Alzheimer's Disease: Testosterone as a Modifier. Journal of Alzheimer's Disease, 59(2), pp. $445^{-466 .}$

Baker-Nigh, A., S. Vahedi, E. Davis, S. Weintraub, E. Bigio, W. Klein and C. Geula (2015). Neuronal amyloid- $ß$ Accumulation Within Cholinergic Basal Forebrain in Aging and Alzheimer's Disease. Brain, 138(6), pp. 1722-1737.

Barnard, N., A. Bunner and U. Agarwal (2014). Saturated and Trans fats and Dementia: A Systematic review. Neurobiology of Aging, 35(2), pp. S65-S73.

Barnes, D. and K. Yaffe (2011). The Projected Effect of Risk Factor Reduction on Alzheimer's Disease Prevalence. Lancet Neurology, 10(9), pp. 819-828.

Beach, T., S. Monsell, L. Phillips and W. Kukull (2012). Accuracy of the Clinical Diagnosis of Alzheimer Disease at National Institute on Aging Alzheimer's Disease Centers. Journal of Neuropathology \& Experimental Neurology, 71(4), pp. 266-273.

Beekly, D., E. Ramos, W. Lee, W. Deitrich, M. Jacka, J. Wu, J. Hubbard, T. Koepsell, J. Morris, W. Kukull and NIA Alzheimer's Disease Centers (2007). The National Alzheimer's Coordinating Center (NACC) Database: The Uniform Data Set. Alzheimer Disease and Associated Disorders, 21(3), pp. 249-258. 
Begley, S. (2016). Alzheimer's Researchers Seethe Over Years of Missteps After Latest Drug Failure. [online] Available at: https://www.statnews.com/2016/07/28/ alzheimers-drug-failure [Accessed 18 May 2017].

Berk, C. and M. Sabbagh (2013). Successes and Failures for Drugs in Late-stage Development for Alzheimer's Disease. Drugs \& Aging, 30 (10), pp. 783-792.

Bharadwaj, P., N. Wijesekara, M. Liyanapathirana, P. Newsholme, L. Ittner, P. Fraser and G. Verdile (2017). The Link Between Type 2 Diabetes and Neurodegeneration: Roles for Amyloid- $§$, Amylin, and Tau Proteins. Journal of Alzheimer's Disease, 59(2), pp. 421-432.

Biessels, G., S. Staekenborg, E. Brunner, C. Brayne and P. Scheltens (2006). Risk of Dementiain Diabetes Mellitus:ASystematic Review.LancetNeurology,5(1),pp.64-74.

Biessels, G., M. Strachan, F. Visseren, L. Kappelle and R. Whitmer (2014). Dementia and Cognitive Decline in Type 2 Diabetes and Prediabetic Stages: Towards Targeted Interventions. Lancet Diabetes Endocrinology, 2(3), pp. 246-255.

Borchelt, D., T. Ratovitski, J. van Lare, M. Lee, V. Gonzales, N. Jenkins, N. Copeland, D. Price and S. Sisodia (1997). Accelerated Amyloid Deposition in the Brains of Transgenic Mice Coexpressing Mutant Presenilin 1 and Amyloid Precursor Proteins. Neuron, 19(4), pp. 939-945.

Braak, H. and E. Braak (1997). Frequency of Stages of Alzheimer-related Lesions in Different Age Categories. Neurobiology of Aging, 18(4), pp. 351-357.

Braak, H. and K. Del Tredici (2011). The Pathological Process Underlying Alzheimer's Disease in Individuals Under Thirty. Acta Neuropathologica, 121(2), pp. 171-181.

Bruce, D., W. Davis, S. Starkstein and T. Davis (2014). Midlife Predictors of Cognitive Impairment and Dementia in Type 2 Diabetes Mellitus: The Fremantle Diabetes Study. Journal of Alzheimer's Disease, 42 (Supp 3), pp. S63-S7o.

Cavanaugh, S., J. Pippin and N. Barnard (2014). Animal Models of Alzheimer Disease: Historical Pitfalls and a Path Forward. Alternatives to Animal Experimentation, 31(3), pp. 279-302.

Chai, C. (2007). The Genetics of Alzheimer's Disease. American Journal of Alzheimer's Disease and Other Dementias, 22(1), pp. 37-41.

Chan, K., W. Wang, J. Wu, L. Liu, E. Theodoratou, J. Car, L. Middleton, T. Russ, I. Deary, H. Campbell and I. Rudan, on behalf of the Global Health Epidemiology Reference Group (GHERG) (2013). Epidemiology of Alzheimer's Disease and Other Forms of Dementia in China, 1990-2010: A Systematic Review and Analysis. Lancet, 381 (9882), pp. 2016-2023.

Chandra, V., M. Ganguli, R. Pandav, J. Johnston, S. Belle and S. DeKosky (1998). Prevalence of Alzheimer's Disease and Other Dementias in Rural India: The Indo-US Study. Neurology, 51(4), pp. 1000-1008.

Charles River (2017). Alzheimer's Disease Research. [online] Available at: http://www .criver.com/products-services/drug-discovery/therapeutic-areas/central-nervous 
-system/biology/in-vivo-study-models/alzheimer-s-disease-model [Accessed 25 April 2017].

Chartier-Harlin, M., F. Crawford, H. Houlden, A. Warren, D. Hughes, L. Fidani, A. Goate, M. Rossor, P. Roques, J. Hardy and M. Mullan (1991). Early-onset Alzheimer's Disease Caused by Mutations at Codon 717 of the $\beta$-Amyloid Precursor Protein Gene. Nature, 353 (6347), pp. 844-846.

Chatterjee, S., S. Peters, M. Woodward, A. Mejia, G. Batty, N. Beckett, A. Beiser, A. Borenstein, P. Crane, M. Haan, L. Hassing, K. Hayden, Y. Kiyohara, E. Larson, C. Li, T. Ninomiya, T. Ohara, R. Peters, T. Russ, S. Seshadri, B. Strand, R. Walker, W. Xu and R. Huxley (2016). Type 2 Diabetes as a Risk Factor for Dementia in Women Compared with Men: A Pooled Analysis of 2.3 Million People Comprising More Than 100,000 Cases of Dementia. Diabetes Care, 39(2), pp. 300-307.

Cheng, G., C. Huang, H. Deng and H. Wang (2012). Diabetes as a Risk Factor for Dementia and Cognitive Impairment: A Meta-analysis of Longitudinal Studies. Internal Medicine Journal, 42(5), pp. 484-491.

Cheng, X., W. Zhou, and Y. Zhang (2014). The Behavioral, Pathological and Therapeutic Features of the Senescence-accelerated Mouse Prone 8 Strain as an Alzheimer's Disease Animal Model. Ageing Research Reviews, 13, pp. 13-37.

ClinicalTrials.gov (n.d.). Search Results for alzheimer| Suspended |Terminated | Completed | Withdrawn Studies. [online] Available at: https://www.clinicaltrials.gov/ ct $2 /$ results?term $=$ alzheimer\&recrs $=$ g\&recrs $=h \&$ recrs $=e \&$ recrs $=i \& a g e \_v=\& g n d r=\&$ type $=\&$ rslt $=\&$ Search $=$ Apply [Accessed 24 July 2017].

Corder, E., A. Saunders, W. Strittmatter, D. Schmechel, P. Gaskell, G. Small, A. Roses, J. Haines and MA Pericak-Vance. (1993). Gene Dose of Apolipoprotein E Type 4 Allele and the Risk of Alzheimer's Disease in Late Onset Families. Science, 261 (5123), pp. 921-923.

Cukierman, T., H. Gerstein and J. Williamson (2005). Cognitive Decline and Dementia in Diabetes - Systematic Overview of Prospective Observational Studies. Diabetologia, 48 (12), pp. 2460-2469.

Cummings, J., T. Morstorf and K. Zhong (2014). Alzheimer's Disease Drug Development Pipeline: Few Candidates, Frequent Failures. Alzheimer's Research \& Therapy, 6(37), pp. $1-7$.

Cummings, J., T. Morstorf and G. Lee (2016). Alzheimer's Drug Development Pipeline: 2016. Alzheimer's \& Dementia: Translational Research \& Clinical Interventions, 2(4), pp. 222-232.

Darrell Royal Research Fund for Alzheimer's Disease (2016). 2016 Request for Funding Application. [online] Available at: http://dkrfund.org/pdfs/DKR2016_RFA.pdf [Accessed 18 May 2017].

De La Monte, S. and J. Wands (2008). Alzheimer's Disease Is Type 3 Diabetes — Evidence Reviewed.Journal of Diabetes Science and Technology, 2(6), pp. 1101-1113. 
Delrieu, J., A. Piau, C. Caillaud, T. Voisin and B. Vellas (2011). Managing Cognitive Dysfunction Through the Continuum of Alzheimer's Disease: Role of Pharmacotherapy. CNS Drugs, 25(3), pp. 213-226.

Do Carmo, S. and A. Cuello (2013). Modeling Alzheimer's Disease in Transgenic Rats. Molecular Neurodegeneration, 8(37).

Dodart, J., C. Mathis, K. Bales and S. Paul (2002). Does My Mouse Have Alzheimer's Disease? Genes, Brain, and Behavior, 1(3), pp. 142-155.

Donohue, M., R. Sperling, R. Petersen, C. Sun, M. Weiner and P. Aisen (2017). Association Between Elevated Brain Amyloid and Subsequent Cognitive Decline Among Cognitively Normal Persons. Journal of the American Medical Association, 317 (22), pp. 2305-2316.

Duyckaerts, C., M. Potier and B. Delatour (2008). Alzheimer Disease Models and Human Neuropathology: Similarities and Differences. Acta Neuropathologica, 115(1), pp. $5^{-38}$.

Eikelenboom, P. and R. Veerhuis (1996). The Role of Complement and Activated Microglia in the Pathogenesis of Alzheimer's Disease. Neurobiology of Aging, 17(5), pp. 673-68o.

Eikelenboom, P., C. Hack, J. Rozemuller and F. Stam (1989). Complement Activation in Amyloid Plaques in Alzheimer's Dementia. Virchows Archiv. B, Cell Pathology Including Molecular Pathology, 56(4), pp. 259-262.

Engelhart, M., M. Geerlings, A. Ruitenberg, J. van Swieten, A. Hofman, J. Witteman and M. Breteler (2002). Dietary Intake of Antioxidants and Risk of Alzheimer Disease. Journal of the American Medical Association, 287 (24), pp. 3223-3229.

Esparza, T., H. Zhao, J. Cirrito, N. Cairns, R. Bateman, D. Holtzman and D. Brody (2013). Amyloid-beta Oligomerization in Alzheimer Dementia Versus High-pathology Controls. Annals of Neurology, 73(1), pp. 104-119.

Esquerda-Canals, G., L. Montoliu, J. Güell-Bosch and S. Villegas (2017). Mouse Models of Alzheimer's Disease. Journal of Alzheimer's Disease, 57(4), pp. 1171-1183.

Exalto, L., R. Whitmer, L. Kappelle and G. Biessels (2012). An Update on Type 2 Diabetes, Vascular Dementia and Alzheimer's Disease. Experimental Gerontology, 47 (11), pp. $85^{8-864 .}$

Garner, J. (2014). The Significance of Meaning: Why Do Over 9o\% of Behavioral Neuroscience Results Fail to Translate to Humans, and What Can We Do to Fix It?. Institute of Laboratory Animal Research Journal, 55(3), pp. 438-456.

Gatz, M., C. Reynolds, L. Fratigioni, B. Johansson, J. Mortimer, S. Berg, A. Fiske and N. Petersen (2006). Role of Genes and Environments for Explaining Alzheimer Disease. Archives of General Psychiatry, 63(2), pp. 168-174.

Geerts, H. (2009). Of Mice and Men: Bridging the Translational Disconnect in CNS Drug Discovery. CNS Drugs, 23 (11), pp. 915-926. 
Giem, P., W. Beeson and G. Fraser (1993). The Incidence of Dementia and Intake of Animal Products: Preliminary Findings from the Adventist Health Study. Neuroepidemiology, 12(1), pp. 28-36.

Glenner, G. and C. Wong (1984). Alzheimer's Disease: Initial Report of the Purification and Characterization of a Novel Cerebrovascular Amyloid Protein. Biochemical and Biophysical Research Communications, 120(3), pp. 885-890.

Goate, A., M. Chartier-Harlin, M. Mullan, J. Brown, F. Crawford, L. Fidani, L. Giuffra, A. Haynes, N. Irving, L. James, R. Mant, P. Newton, K. Rooke, P. Roques, C. Talbot, M. Pericak-Vance, A. Roses, R. Williamson, M. Rossor, M. Owen and J. Hardy (1991). Segregation of a Missense Mutation in the Amyloid Precursor Protein Gene with Familial Alzheimer's Disease. Nature, 349 (6311), pp. 704-706.

Graf, C., R. Cécile, S. Giannelli, B. Nobari, G. Gold, F. Herrmann and D. Zekry (2014). Vitamin D Is Not Associated with Cognitive Status in a Cohort of Very Old Hospitalized Patients. Journal of Alzheimer's Disease, 42 (Supp 3), pp. S53-S61.

Grant, W.B. (2014). Trends in Alzheimer's disease during the nutrition transition in Japan and developing countries. Journal of Alzheimer's Disease, 38(3), pp. 611-620.

Gross, A., H. Lu, L. Meoni, J. Gallo, J. Schrack and A. Sharrett (2017). Physical Activity in MIDLIFE IS NOT Associated with Cognitive Health in Later Life Among Cognitively Normal Adults. Journal of Alzheimer's Disease, 59(4), pp. 1349-1358.

Gudala, K., D. Bansal, F. Schifano and A. Bhansali (2013). Diabetes Mellitus and Risk of Dementia: A Meta-analysis of prospective observational studies. Journal of Diabetes Investigation, 4(6), pp. 640-650.

Guerrero, A., C. Dorado-Martinez, A. Rodriguez, K. Pedroza-Rios, G. Borgonio-Pérez and S. Rivas-Arancibia (1999). Effects of Vitamin E on Ozone-induced Memory Deficits and Lipid Peroxidation in Rats. Neuroreport, 10(8), pp. 1689-1692.

Hamer, M. and Y. Chida (2009). Physical Activity and Risk of Neurodegenerative Disease: A Systematic Review of Prospective Evidence. Psychological Medicine, 39(1), pp. $3^{-11 .}$

Hampel, H., K. Blennow, L. Shaw, Y. Hoessler, H. Zetterberg and J. Trojanowski (2010). Total and Phosphorylated Tau Protein as Biological Markers of Alzheimer's Disease. Experimental Gerontology, 45(1), pp. 30-40.

Hardy, J. (2006). Alzheimer's Disease: The Amyloid Cascade Hypothesis: An Update and Reappraisal. Journal of Alzheimer's Disease, 9(Supp 3), pp. 151-153.

Hardy, J. and D. Allsop (1991). Amyloid Deposition as the Central Event in the Aetiology of Alzheimer's Disease. Trends in Pharmacological Sciences, 12, pp. 383-388.

Hardy, J. and G. Higgins (1992). Alzheimer's Disease: The Amyloid Cascade Hypothesis. Science, 256 (5054), pp. 184-185.

Hardy, J. and D. Selkoe (2002). The Amyloid Hypothesis of Alzheimer's Disease: Progress and Problems on the Road to Therapeutics. Science, 297 (5580), pp. 353-356. 
Haroutunian, V., M. Schnaider-Beeri, J. Schmeidler, M. Wysocki, D. Purohit, D. Perl, L. Libow, G. Lesser, M. Maroukian and H. Grossman (2008). Role of the Neuropathology of Alzheimer Disease in Dementia in the Oldest-old. Archives of Neurology, 65(9), pp. 1211-1217.

Hebert, L., J.Weuve, P. Scherr and D. Evans (2013). Alzheimer Disease in the United States (2010-2050) Estimated Using the 2010 Census. Neurology, 80 (19), pp. 1778-1783.

Help for Alzheimer's Families (2012). Americans Rank Alzheimer's as Most Feared Disease. [online] Available at: http://www.helpforalzheimersfamilies.com/alzheimers -dementia-care-services/alzheimers_feared_disease/[Accessed 18 April 2017].

Helzner, E., N. Scarmeas, S. Cosentino, M. Tang, N. Schupf and Y. Stern (2008). Survival in Alzheimer Disease: A Multi-ethnic, Population-based Study of Incident Cases. Neurology, 71 (19), pp. 1489-1495.

Henriques, C. (2017). 35 Therapies in Phase 2 and 3 Clinical Trials Raise Hopes in Alzheimer's Community. Alzheimer's News Today. [online] Available at: alzheimersnewstoday.com/2017/07/19/alzheimers-community-takes-hope-from -the-many-therapies-that-are-in-or-heading-for-trials [Accessed 24 July 2017].

Hoffmann, K., N. Sobol, K. Frederiksen, N. Beyer, A. Vogel, K. Vestergaard, H. Brændgaard, H. Gottrup, A. Lolk, L. Wermuth, S. Jacobsen, L. Laugesen, R. Gergelyffy, P. Høgh, E. Bjerregaard, B. Andersen, V. Siersma, P. Johannsen, C. Cotman, G. Waldemar and S. Hasselbalch (2016). Moderate-to-high Intensity Physical Exercise in Patients with Alzheimer's Disease: A Randomized Controlled Trial.Journal of Alzheimer's Disease, 5o(2), pp. 443-453.

International Monetary Fund (2017). Reportfor Selected Countries and Subjects. [online] Availableat:http://www.imf.org/external/pubs/ft/weo/2017/o1/weodata/index.aspx [Accessed 23 August 2017].

Jackson Laboratory (2017). Alzheimer's Mouse Model Resource. [online] Available at: https://www.jax.org/research-and-faculty/research-centers/alzheimers-diseasecenter/alzheimers-mouse-model-repository [Accessed 20 April 2017].

James, B., S. Leurgans, L. Hebert, P. Scherr, K. Yaffe and D. Bennett (2014). Contribution of Alzheimer Disease to Mortality in the United States. Neurology, 82 (12), pp. $1045^{-1050 .}$

Jansen, W., R. Ossenkoppele, D. Knol, B. Tijms, P. Scheltens, F. Verhey, P. Visser and the Amyloid Biomarker Study Group (2015). Prevalence of Cerebral Amyloid Pathology in Persons without Dementia: A Meta-analysis. Journal of the American Medical Association, 313 (19), pp. 1924-1938.

Jick, H., G. Zornberg, S. Jick, S. Seshadri and D. Drachman (2000). Statins and the Risk of Dementia. Lancet, 356 (9242), pp. 1627-1631.

Joseph,J., B.Shukitt-Hale,N.Denisova, R.Prior,G.Cao,A.Martin,G.TaglialatelaandP.Bickford (1998). Long-term Dietary Strawberry, Spinach, or Vitamin E Supplementation 
Retards the Onset of Age-related Neuronal Signal-transduction and Cognitive Behavioral Deficits. Journal of Neuroscience, 18 (19), pp. 8047-8055.

Kalmijn, S., L. Launer, A. Ott, J. Witteman, A. Hofman and M. Breteler (1997). Dietary Fat Intake and the Risk of Incident Dementia in the Rotterdam Study. Annals of Neurology, 42(5), pp. 776-782.

Kennelly, S., B. Lawlor and R. Kenny (2009a). Blood Pressure and Dementia A Comprehensive Review. Therapeutic Advances in Neurological Disorders, 2(4), pp. 241-26o.

Kennelly, S., B. Lawlor and R. Kenny (200gb). Blood Pressure and the Risk for Dementia-A Double-edged Sword. Ageing Research Reviews, 8(2), pp. 61-70.

Kikuya, M., T. Ohkubo, H. Metoki, K. Asayama, H. Hara, T. Obara, R. Inoue, H. Hoshi, J. Hashimoto, K. Totsune, H. Satoh and Y. Imai (2008). Day-by-day Variability of Blood Pressure and Heart Rate at Home as a Novel Predictor of Prognosis: The Ohasama Study. Hypertension, 52(6), pp. 1045-1050.

Kolarova, M., U. Sengupta, A. Bartos, J. Ricny and R. Kayed (2017). Tau Oligomers in Sera of Patients with Alzheimer's Disease and Aged Controls. Journal of Alzheimer's Disease, $58(2)$, pp. 471-478.

Kopf, D. and L. Frolich (2009). Risk of Incident Alzheimer's Disease in Diabetic Patients: A Systematic Review of Prospective Trials. Journal of Alzheimer's Disease, 16(4), pp. 677-685.

Kosik, K., C. Joachim and D. Selkoe (1986). Microtubule-associated Protein Tau ( $\tau)$ Is a Major Antigenic Component of Paired Helical Filaments in Alzheimer Disease. Proceedings of the National Academy of Sciences, 83 (11), pp. 4044-4048.

Kumar, A., A. Aggarwal, A. Singh and P. Naidu (2016). Animal Models in Drug Discovery of Alzheimer's Disease: A Mini Review. EC Pharmacology and Toxicology, 2.1, pp. 6o-79.

Langa, K., E. Larson, E. Crimmins, L.D. Fau, D. Levine, M. Kabeto and D. Weir (2017). A Comparison of the Prevalence of Dementia in the United States in 2000 and 2012. Journal of the American Medical Association, Internal Medicine, 177(1), pp. 51-58.

Langley, G. (2014). Considering a New Paradigm for Alzheimer's Disease Research. Drug Discovery Today, 19(8), pp. 1114-1124.

Lautenschlager, N., K. Cox, L. Flicker, J. Foster, F. van Bockxmeer, J. Xiao, K. Greenop and O. Almeida (2008). Effect of Physical Activity on Cognitive Function in Older Adults at Risk for Alzheimer Disease: A Randomized Trial. Journal of the American Medical Association, 300(9), pp. 1027-1037.

Levy-Lahad, E., W. Wasco, P. Poorkaj, D. Romano, J. Oshima, W. Pettingell, C. Yu, P. Jondro, S. Schmidt, K. Wang, A. Crowley, Y. Fu, S. Guenette, D. Galas, E. Nemens, E. Wijsman, T. Bird, G. Schellenberg and R. Tanzi (1995). Candidate Gene for the Chromosome 1 Familial Alzheimer's Disease Locus. Science, 269 (5226), pp. 973-977. 
Li, J., M. Cesari, F. Liu, B. Dong and B. Vellas (2017). Effects of Diabetes Mellitus on Cognitive Decline in Patients with Alzheimer Disease: A Systematic Review. Canadian Journal of Diabetes, 41(1), pp. 114-119.

Littlejohns, T., W. Henley, I. Lang, C. Annweiler, O. Beauchet, P. Chaves, L. Fried, B. Kestenbaum, L. Kuller, K. Langa, O. Lopez, K. Kos, M. Soni and D. Llewellyn (2014). Vitamin D and the Risk of Dementia and Alzheimer Disease. Neurology, 83 (10), pp. 920-928.

Lok, K., H. Zhao, C. Zhang, N. He, H. Shen, Z. Wang, W. Zhao and M. Yin (2013) Effects of Accelerated Senescence on Learning and Memory, Locomotion and Anxiety-like Behavior in APP/PS1 Mouse Model of Alzheimer's Disease. Journal of the Neurological Sciences, 335 (1-2), pp. 145-154.

Lopez, O., J. Becker, Y. Chang, R. Sweet, S. DeKosky, M. Gach, O. Carmichael, E. McDade and L. Kuller (2012). Incidence of Mild Cognitive Impairment in the Pittsburgh Cardiovascular Health Study-Cognition Study. Neurology, 79 (15), pp. 1599-16o6.

Lovell-Badge, R. (2013). Nine Out of Ten Statistics Are Taken Out of Context. Understanding Animal Research. [online] Available at: http://www.understandinganimal research.org.uk/news/communications-media/nine-out-of-ten-statistics-are -taken-out-of-context [Accessed 8 May 2017].

Lu, F., K. Lin and H. Kuo (2009). Diabetes and the Risk of Multi-system Aging Phenotypes: A Systematic Review and Meta-analysis. PLoS One, 4(1), pp. 4144ff.

Luchsinger, J., M-X. Tang, S. Shea and R. Mayeux (2002). Caloric Intake and the Risk of Alzheimer Disease. Archives of Neurology, 59(8), pp. 1258-1263.

Luchsinger, J., M.X. Tang, S. Shea and R. Mayeux (2003). Antioxidant Vitamin Intake and Risk of Alzheimer Disease. Archives of Neurology, 6o(2), pp. 203-208.

Masters, C., G. Simms, N. Weinman, G. Multhaupt, B. McDonald and K. Beyreuthert (1985). Amyloid Plaque Core Protein in Alzheimer Disease and Down Syndrome. Proceedings of the National Academy of Sciences, 82 (12), pp. 4245-4249.

Matsumoto, A., M. Satoh, M. Kikuya, T. Ohkubo, M. Hirano, R. Inoue, T. Hashimoto, A. Hara, T. Hirose, T. Obara, H. Metoki, K. Asayama, A. Hosokawa, K. Totsune, H. Hoshi, T. Hosokawa, H. Sato and Y. Imai (2014). Day-to-day Variability in Home Blood Pressure Is Associated with Cognitive Decline: The Ohasama Study. Hypertension, $63(6)$, pp. $1333^{-1338 .}$

McDade, E. and R. Bateman (2017). Stop Alzheimer's before it starts. Nature, 547 (7662), pp. $153^{-155}$.

McDonald, C., M. Pearce, S. Kerr and J. Newton (2017). Blood Pressure Variability and Cognitive Decline in Older People: A 5-year Longitudinal Study. Journal of Hypertension, 35(1), pp. 140-147.

McGuinness, B., D. Craig, R. Bullok and P. Passmore (2016). Statins for the Prevention of Dementia. Cochrane. [online] Available at: http://www.cochrane.org/CDoo316o/ DEMENTIA_statins-prevention-dementia [Accessed 14 August 2017]. 
Mitchell, A. and M. Shiri-Feshki (2009). Rate of Progression of Mild Cognitive Impairment to Dementia: Meta-analysis of 41 Robust Inception Cohort Studies. Acta Psychiatrica Scandinavica, 119(4), pp. 252-265.

Mitka, M. (2006). Guidelines Aim to Speed Drug Approval While Protecting Human Subjects. Journal of the American Medical Association, 295(9), pp. 988-989.

Monsell, S., C. Mock, C. Roe, N. Ghoshal, J. Morris, N. Cairns and W. Kukull (2013). Comparison of Symptomatic and Asymptomatic Persons with Alzheimer Disease Neuropathology. Neurology, 8o(23), pp. 2121-2129.

Monsell, S., W. Kukull, A. Roher, C. Maarouf, G. Serrano, T. Beach, R. Caselli, T. Montine and E. Reiman (2015). Characterizing Apolipoprotein E $\varepsilon 4$ Carriers and Noncarriers with the Clinical Diagnosis of Mild to Moderate Alzheimer Dementia and Minimal ß-amyloid Peptide Plaques. Journal of the American Medical Association, Neurology, 72(10), pp. 1124-1131.

Moore, C. (2017). Patient Advocacy Groups Welcome 40\% Increase in Alzheimer's NIH Research Funds Authorized by Congress. Alzheimer's News Today. [online] Available at: alzheimersnewstoday.com/2017/05/og/alzheimers-groups-welcome-40-increase -nih-research-funds-authorized-congress/ [Accessed 17 May 2017].

Morris, G.P., I.A. Clark and B. Vissel (2014). Inconsistencies and Controversies Surrounding the Amyloid Hypothesis Of Alzheimer's Disease. Acta Neuropathologica Communications, 2(1), p. 135 .

Morris, M., D. Evans, J. Bienias, C. Tangney, D. Bennett, N. Aggarwal, R. Wilson and P. Scherr (2002). Dietary Intake of Antioxidant Nutrients and the Risk of Incident Alzheimer Disease in a Biracial Community Study. Journal of the American Medical Association, 287(24), pp. 3230-3237.

Morris, M., D. Evans, J. Bienias, C. Tangney, D. Bennett, N. Aggarwal, J. Schneider and R. Wilson (2003). Dietary Fats and the Risk of Incident Alzheimer Disease. Archives of Neurology, 6o(2), pp. 194-200.

Mullan, M., F. Crawford, K. Axelman, H. Houlden, L. Lilius, B. Winblad and L. Lannfelt (1992). A Pathogenic Mutation for Probable Alzheimer's Disease in the APP Gene at the N-terminus of Beta-amyloid. Nature Genetics, 1(5), pp. 345-347.

Mullin, E. (2017). Amyloid-busting Drugs for Alzheimer's Keep Failing, But So Does Everything Else. MIT Technology Review. [online] Available at: https://www .technologyreview.com/s/603744/amyloid-busting-drugs-for-alzheimers-keep -failing-but-so-does-everything-else [Accessed 11 May 2017].

Neha, R. Sodhi, A. Jaggi and N. Singh (2014). Animal Models of Dementia and Cognitive Dysfunction. Life Sciences, $109(2)$, pp. 73-86.

Notkola, I., R. Sulkava, J. Pekkanen, T. Erkinjuntti, C. Ehnholm, P. Kivinen, J. Tuomilehto and A. Nissinen (1998). Serum total cholesterol, apolipoprotein E epsilon 4 allele, and Alzheimer's disease. Neuroepidemiology, 17(1), pp. 14-20.

O'Connor, A. (1998). Discussion of the validation of animal testing by the FDA. (Personal communication with André Menache). 
Oddo, S., A. Caccamo, J. Shepherd, M. Murphy, T. Golde, R. Kayed, R. Metherate, M. Mattson, Y. Akbari and F. LaFerla (2003). Triple-transgenic Model of Alzheimer's Disease with Plaques and Tangles: Intracellular Abeta and Synaptic Dysfunction. Neuron, 39(3), pp. 409-421.

Oishi, E., T. Ohara, S. Sakata, M. Fukuhara, J. Hata, D. Yoshida, M. Shibata, T. Ohtsubo, T. Kitazono, Y. Kiyohara and T. Ninimiya (2017). Day-to-day Blood Pressure Variability and Risk of Dementia in a General Japanese Elderly Population: The Hisayama Study. Circulation, 136(6), pp. 516-525.

Olsson, B., R. Lautner, U. Andreasson, A. Öhrfelt, E. Portelius, M. Bjerke, M. Hölttä, C. Rosén, C Olsson, G. Strobel, E. Wu, K. Dakin, M. Petzold, K. Blennow and H. Zetterberg (2016). CSF and Blood Biomarkers for the Diagnosis of Alzheimer's Disease: A Systematic Review and Meta-analysis. Neurology, 15(7), pp. 673-684.

Palatini, P. (2014). Day-by-day Blood Pressure Variability: Cause or Consequence of Vascular Brain Injury? Hypertension, 63(6), pp. 1163-1165.

Pallàs, M. (2012). Senescence-accelerated Mice P8: A Tool to Study Brain Aging and Alzheimer's Disease in a Mouse Model. International Scholarly Research Notices Cell Biology, (Article ID 917167), pp. 1-12.

Pharmaceutical Research and Manufacturers of America (PhRMA) (2012). Researching Alzheimer's Medicines: Setbacks and Stepping Stones. [online] Available at: http://phrma-docs.phrma.org/sites/default/files/pdf/alzheimersetbacksreport.pdf [Accessed 10 May 2017].

PhRMA (2015). Researching Alzheimer's Medicines: Setbacks and Stepping Stones. [online] Available at: http://phrma-docs.phrma.org/sites/default/files/pdf/ alzheimersetbacksreportfinal912.pdf [Accessed 10 May 2017].

PhRMA (2016). 2016 Medicines in Development for Alzheimer's Disease. [online] Available at http://phrm-docs.phrma.org/sites/default/files/pdf/medicines-in -development-drug-list-alzheimers.pdf [Accessed 11 May 2017].

Pistollato, F., E. Ohayon, A. Lam, G. Langley, T. Novak, D. Pamies, G. Perry, E. Trushina, R. Williams, A. Roher, T. Hartung, S. Harnad, N. Barnard, M. Morris, M. Lai, R. Merkley and P. Chandrasekera (2016). Alzheimer Disease Research in the $21^{\text {st }}$ Century: Past and Current Failures, New Perspectives and Funding Priorities. Oncotarget, 7(26), pp. 38999-39016.

Porquet, D., P. Andres-Benito, C. Grinan-Ferre, A. Camins, I. Ferrer, A. Canudas, J. Del Valle and M. Pallàs (2015). Amyloid and Tau Pathology of Familial Alzheimer's Disease APP/PS1 Mouse Model in a Senescence Phenotype Background (SAMP8). Age (Dordrecht, Netherlands), 37(12), pp. 1-17.

Price, J., D. McKeel Jr., V. Buckles, C. Roe, C. Xiong, M. Grundman, L. Hansen, R. Petersen, J. Parisi, D. Dickson, C. Smith, D. Davis, F. Schmitt, W. Markesbery, J. Kaye, R. Kurlan, C. Hulette, B. Kurland, R. Higdon, W Kukull, and J. Morris (2009). Neuropathology of Nondemented Aging: Presumptive Evidence for Preclinical Alzheimer Disease. Neurobiology of Aging, 30(7), pp. 1026-1036. 
Purnell, C., S. Gao, C. Callahan and H. Hendrie (2009). Cardiovascular Risk Factors and Incident Alzheimer Disease: A Systematic Review of the Literature. Alzheimer Disease and Associated Disorders, 23(1), pp. 1-18.

Puzzo, D., L. Lee, A. Palmeri, G. Calabrese, and O. Arancio (2014). Behavioral Assays with Mouse Models of Alzheimer's Disease: Practical Considerations and Guidelines. Biochemical Pharmacology, 88(4), pp. 450-467.

Qiu, C., B. Winblad and L. Fratiglioni (2005). The Age-dependent Relation of Blood Pressure to Cognitive Function and Dementia. Lancet Neurology, 4(8), pp. 487-499.

Ramachandran, T. (2016). Alzheimer Disease Imaging. Medscape. [online] Available at: http://emedicine.medscape.com/article/336281-overview [Accessed 12 May 2017].

Richard, E. and C. Brayne (2014). Mild Cognitive Impairment - Not Always What It Seems. Nature Reviews Neurology, 10, pp. 130-131.

Roberts, R., D. Knopman, M. Mielke, R. Cha, V. Pankratz, T. Christianson, Y. Geda, B. Boeve, R. Ivnik, E. Tangalos, W. Rocca and R. Petersen (2014a). Higher Risk of Progression to Dementia in Mild Cognitive Impairment Cases Who Revert to Normal. Neurology, 82(4), pp. 317-325.

Roberts, R., D. Knopman, Y. Geda, R. Cha, V. Pankratz, L. Baertlein, B. Boeve, E. Tangalos, R. Ivnik, M. Mielke and R. Petersen (2014b). Association of Diabetes with Amnestic and Nonamnestic Mild Cognitive Impairment. Alzheimer's \& Dementia, 10(1), Pp. 18-26.

Rolland, Y., G. Abellan van Kan and B. Vellas (2008). Physical Activity and Alzheimer's Disease: From Prevention to Therapeutic Perspectives. Journal of the American Medical Directors Association, 9(6), pp. 390-405.

Rosenberg, P. (2005). Clinical Aspects of Inflammation in Alzheimer's Disease. International Review of Psychiatry, 17 (6), pp. 503-514.

Ross, C. and M. Poirier (2004). Protein Aggregation and Neurodegenerative Disease. Nature Medicine, 10(7), pp. S10-S17.

Rossor, M., N. Fox, P. Freeborough and R. Harvey (1996). Clinical Features of Sporadic and Familial Alzheimer's Disease. Neurodegeneration, 5(4), pp. 393-397.

Rothwell, P., S. Howard, E. Dolan, E. O'Brien, J. Dobson, B. Dahlöf, P. Sever and N. Poulter (2010). Prognostic Significance of Visit-to-visit variability, Maximum Systolic Blood Pressure, and Episodic Hypertension. Lancet, 375(9718), pp. 895-905.

Sabayan, B., L. Wijsman, J. Foster-Dingley, D. Stott, I. Ford, B. Buckley, N. Sattar, J. Jukema, M. van Osch, J. van der Grond, M. van Buchem, R. Westendorp, A. de Craen and S. Mooijaart (2013). Association of Visit-to-visit Variability in Blood Pressure with Cognitive Function in Old Age: Prospective Cohort Study. The British Medical Journal, 347, p. f46oo.

Sadigh-Eteghad, S., M. Talebi and M. Farhoudi (2012). Association of Apolipoprotein E Epsilon 4 Allele with Sporadic Late Onset Alzheimer's Disease. A Meta-analysis. Neurosciences (Riyadh), 17(4), pp. 321-326. 
Satizabal, C., A. Beiser, V. Chouraki, G. Chêne, C. Dufouil and S. Seshadri (2016). Incidence of Dementia Over Three Decades in the Framingham Heart Study. New England Journal of Medicine, 374(6), pp. 523-532.

Schneider, L., F. Mangialasche, N. Andreasen, H. Feldman, E. Giacobini, R. Jones, V. Mantua, P. Mecocci, L. Pani, B. Winblad and M. Kivipelto (2014). Clinical Trials and Late-stage Drug Development for Alzheimer's Disease: An Appraisal from 1984 to 2014. Journal of Internal Medicine, 275(3), pp. 251-283.

Serrano-Pozo, A., J. Qian, S. Monsell, D. Blacker, T. Gómez-Isla, R. Betensky, J. Growdon, K. Johnson, M. Frosch, R. Sperling and B. Hyman (2014). Mild to Moderate Alzheimer Dementia with Insufficient Neuropathological Changes. Annals of Neurology, 75(4), pp. 597-601.

Shakoor, S. J. Carroll F. Arsalan and Endpoints News Team (2017). Alzheimer's: Learning from a Legacy of Bitter Setbacks. Endpoints News [online] Available at: https:// endpts.com/special/alzheimers-2017/ [Accessed 2 May 2017].

Singh, A. and P. Henske (2003). Has the Pharmaceutical Blockbuster Model Gone Bust?. Bain \& Company, News release. [online] Available at: http://www.bain.com/about/ press/press-releases/has-the-pharmaceutical-blockbuster-model-gone-bust.aspx [Accessed 8 May 2017].

Sink, K., M. Espeland, C. Castro, T. Church, R. Cohen, J. Dodson, J. Guralnik, H. Hendrie, J. Jennings, J. Katula, O. Lopez, M. McDermott, M. Pahor, K. Reid, J. Rushing, J. Verghese, S. Rapp, J. Williamson and LIFE Study Investigators (2015). Effect of a 24-month Physical Activity Intervention Vs Health Education on Cognitive Outcomes in Sedentary Older Adults: The LIFE Randomized Trial.Journal of the American Medical Association, 314(8), pp. 781-790.

Socci, D., B. Crandall and G. Arendash (1995). Chronic Antioxidant Treatment Improves the Cognitive Performance of Aged Rats. Brain Research, 693(1-2), pp. 88-94.

Sofi, F., D. Valecchi, D. Bacci, R. Abbate, G. Gensini, A. Casini and C. Macchi (2010). Physical Activity and Risk of Cognitive Decline: A Meta-analysis of Prospective Studies. Journal of Internal Medicine, 269(1), pp. 107-117.

Solfrizzi, V., C. Custodero, M. Lozupone, B. Imbimbo, V. Valiani, P. Agosti, A. Schilardi, A. D'Introno, M. La Montagna, M. Calvani, V. Guerra, R. Sardone, A. Bellomo, A. Greco, A. Daniele, D. Seripa, G. Logroscino, C. Sabbá and F. Panza (2017). Relationships of Dietary Patterns, Foods, and Micro- and Macronutrients with Alzheimer's Disease and Late-life Cognitive Disorders: A Systematic Review. Journal of Alzheimer's Disease, 59(3), pp. 815-849.

Strittmatter, W., A. Saunders, D. Schmechel, M. Pericak-Vance, J. Enghild, G. Salvesen and A. Roses (1993). Apolipoprotein E: High-avidity Binding to Beta-amyloid and Increased Frequency of Type 4 Allele in Late-onset Familial Alzheimer Disease. Proceedings of the National Academy of Academic Sciences, 90(5), pp. 1977-1981. 
Sutherland, G.T, Lim J., Srikanth, V. and Bruce, D.G., 2017. Epidemiological approaches to understanding the link between type 2 diabetes and dementia. Journal of Alzheimer's Disease, 59(2), pp. 393-403.

Taconic Biosciences, Inc. (2017). Alzheimer's Disease Models. [online] Available at: https://www.taconic.com/find-your-model/neuroscience-portfolio/alzheimersdisease-models/ [Accessed 25 April 2017].

Taylor, C., S. Greenlund, L. McGuire, H. Lu and J. Croft (2017). Deaths from Alzheimer's Disease - United States, 1999-2014. Morbidity and Mortality Weekly Report, 66 (20), pp. $5^{21-526 .}$

Terry, R., E. Masliah, D. Salmon, N. Butters, R. DeTeresa, R. Hill, L. Hansen and R. Katzman (1991). Physical Basis of Cognitive Alterations in Alzheimer's Disease: Synapse Loss Is the Major Correlate of Cognitive Impairment. Annals of Neurology, 30(4), pp. 572-580.

Thal, D., L. Grinberg and J. Attems (2012). Vascular Dementia: Different Forms of Vessel Disorders Contribute to the Development of Dementia in the Elderly Brain. Experimental Gerontology, 47(11), pp. 816-824.

Toots, A., H. Littbrand, G. Boström, C. Hörnsten, H. Holmberg, L. Lundin-Olsson, N. Lindelöf, Y. Gustafson and E. Rosendahl (2017). Effects of Exercise on Cognitive Function in Older People with Dementia: A Randomized Controlled Trial. Journal of Alzheimer's Disease, doi: 10.3233/JAD-170014 [Epub ahead of print], pp. 1-10.

UK Parliament (2004). Animal Experiments. [online] Available at: https://www .publications.parliament.uk/pa/cm200304/cmhansrd/voo40331/text/40331wo6 .htm\#40331w06.html_sbhdo [Accessed 8 May 2017].

Us Against Alzheimer's (2017). Alzheimer's Drugs in Development Pipeline. [online] Available at: http://www.usaagainstalzheimers.org/sites/default/files/alzheimersdrugs-development-pipeline-2017.pdf [Accessed 24 July 2017].

us Burden of Disease Collaborators (2013). The State of Us Health, 1990-2010. Journal of the American Medical Association, 310(6), pp. 591-6o8.

us Food and Drug Administration (FDA) (2004). Challenges and Opportunities Report - March 2004. [online] Available at: http://wayback.archive-it .org/7993/20180125032208/https://www.fda.gov/ScienceResearch/SpecialTopics/ CriticalPathInitiative/CriticalPathOpportunitiesReports/ucmo77262.htm [Accessed 8 May 2017].

Veerhuis, R. (2011). Histological and Direct Evidence for the Role of Complement in the Neuroinflammation of Alzheimer's Disease. Current Alzheimer Research, 8(1), pp. 34-58.

Wachterman, M., D. Kiely and S. Mitchell (2008). Reporting Dementia on the Death Certificates of Nursing Home Residents Dying with End-stage Dementia.Journal of the American Medical Association, 300(22), pp. 2608-2610. 
Wang, L., T. Benzinger, Y. Su, J. Christensen, K. Friedrichsen, P. Aldea, J. McConathy, N. Cairns, A. Fagan, J. Morris and B. Ances (2016). Evaluation of Tau Imaging in Staging Alzheimer Disease and Revealing Interactions Between $\beta$-amyloid and Tauopathy. Journal of the American Medical Association, Neurology, 73(9), pp. 1070-1077.

Ward, A., S. Tardiff, C. Dye and H Arrighi (2013). Rate of Conversion from Prodromal Alzheimer's Disease to Alzheimer's Dementia: A Systematic Review of the Literature. Dementia and Geriatric Cognitive Disorders Extra, 3(1), pp. 320-332.

Webster, S., A. Bachstetter, P. Nelson, F. Schmitt and L. Van Eldik (2014). Using Mice to Model Alzheimer's Dementia: An Overview of the Clinical Disease and the Preclinical Behavioral Changes in 10 Mouse Models. Frontiers in Genetics, 5, p. 88.

Weuve, J., L. Hebert, P. Scherr and D. Evans (2014). Deaths in the United States Among Persons with Alzheimer's Disease. Alzheimer's \& Dementia, 10(2), pp. e40-e46.

Wolozin, B., W. Kellman, P. Ruosseau, G. Celesia and G. Siegel (200o). Decreased Prevalence of Alzheimer Disease Associated with 3-hydroxy-3-methylglutaryl Coenzyme a Reductase Inhibitors. Archives of Neurology, 57(10), pp. 1439-1443.

Wood, J., S. Mirra, N. Pollock and L. Binder (1986). Neurofibrillary Tangles of Alzheimer Disease Share Antigenic Determinants with the Axonal Microtubule-associated Protein Tau $(\tau)$. Proceedings of the National Academy of Sciences, 83 (11), pp. 4040-4043.

World Bank (2017). GDP (current us\$). [online] Available at: http://data.worldbank .org/indicator/NY.GDP.MKTP.CD?year_high_desc=true [Accessed 23 August 2017]. World Health Organization (2015). 10 Facts on Dementia. [online] Available at: http:// www.who.int/features/factfiles/dementia/en/ [Accessed 18 April 2017].

Yaffe, K., C. Falvey, N. Hamilton, A. Schwartz, E. Simonsick, S. Satterfield, J. Cauley, C. Rosano, L. Launer, E. Strotmeyer and T. Harris (2012). Diabetes, Glucose Control, and 9-year Cognitive Decline Among Older Adults without Dementia. Archives of Neurology, 69(9), pp. 1170-1175.

Yamada, K., T. Tanaka, D. Han, K. Senzaki, T. Kameyama and T. Nabeshima (1999). Protective Effects of Idebenone and Alpha-tocopherol on Beta-amyloid-(1-42)induced Learning and Memory Deficits in Rats: Implication of Oxidative Stress in Beta-amyloid-induced Neurotoxicity In Vivo. European Journal of Neuroscience, 11(1), pp. 83-90.

Zahs, K. and K. Ashe (2010). “Too Much Good News.” Are Alzheimer Mouse Models Trying to Tell Us How to Prevent, Not Cure, Alzheimer's Disease? Trends in Neurosciences, $33(8)$, pp. $381-389$.

Zhang, J., C. Chen, S. Hua, H. Liao, M. Wang, Y. Xiong and F. Cao (2017). An Updated Meta-analysis of Cohort Studies: Diabetes and Risk of Alzheimer's Disease. Diabetes Research and Clinical Practice, 124, pp. 41-47.

Zilkens, R., W. Davis, K. Spilsbury, J. Semmens and D. Bruce (2013). Earlier Age of Dementia Onset and Shorter Survival Times in Dementia Patients with Diabetes. American Journal of Epidemiology, 7(11), pp. 1246-1254. 


\section{Recommended Reading, Not Referenced in the Text $A D$ Risk Factors, Biomarkers, and Management}

Alzheimer's Society (UK) (2017). Risk Factors and Prevention. [online] Available at https://www.alzheimers.org.uk/info/20010/risk_factors_and_prevention [Accessed 30 May 2017].

Hane, F., M. Robinson, B. Lee, O. Bai, Z. Leonenko and M. Albert (2017). Recent Progress in Alzheimer's Disease Research, Part 3: Diagnosis and Treatment. Journal of Alzheimer's Disease, $57(3)$, pp. 645-665.

Itzhaki, R., R. Lathe, B. Balin, M. Ball, E. Bearer, H. Braak, M. Bullido, C. Carter, M. Clerici, S. Cosby, K. Del Tredici, H. Field, T. Fulop, C. Grassi, W. Griffin, J. Haas, A. Hudson, A. Kamer, D. Kell, F. Licastro, L. Letenneur, H. Lövheim, R. Mancuso, J. Miklossy, C. Otth, A. Palamara, G. Perry, C. Preston, E. Pretorius, T. Strandberg, N. Tabet, S. Taylor-Robinson and J. Whittum-Hudson (2016). Microbes and Alzheimer's Disease. Journal of Alzheimer's Disease, 51(4), pp. 979-984.

Mayeda, E., M. Glymour, C. Quesenberry and R. Whitmer (2016). Inequalities in Dementia Incidence Between Six Racial and Ethnic Groups Over 14 Years. Alzheimer's \& Dementia, 12(3), pp. 216-224.

Robinson, M., B. Lee and F. Hane (2017). Recent Progress in Alzheimer's Disease Research, Part 2: Genetics and Epidemiology. Journal of Alzheimer's Disease, 57(2), pp. 317-330.

Sharma, N. and Q. Singh (2016). Exploring Biomarkers for Alzheimer's Disease. Journal of Clinical and Diagnostic Research, 10(7), pp. KEo1-KEo6.

Vos, S., I.M. van Boxte, O. Schiepers, K. Deckers, M. de Vugt, I. Carrière, J. Dartigues, K. Peres, S. Artero, K. Ritchie, L. Galluzzo, E. Scafato, G. Frisoni, M. Huisman, H. Comijs, S. Sacuiu, I. Skoog, K. Irving, C. O’Donnell, F. Verhey, P. Visser and S. Köhler (2017). Modifiable Risk Factors for Prevention of Dementia in Midlife, Late Life, and the Oldest-old: Validation of the LIBRA Index. Journal of Alzheimer's Disease, doi:10.3233/JAD-161208 (e-pub ahead of print).

Wingbermühle, R., K. Wen, F. Wolters, M. Ikram and D. Bos (2017). Smoking, APOE Genotype, and Cognitive Decline: The Rotterdam Study. Journal of Alzheimer's Disease, 57(4), pp. 1191-1195.

Yegambaram, M., B. Manivannam, T. Beach and R. Halden (2015). Role of Environmental Contaminants in the Etiology of Alzheimer's Disease: A Review. Current Alzheimer Research, 12(2), pp. 116-146.

\section{Human-relevant Research Methods to Replace Animal Research}

Brownjohn, P., J. Smith, E. Portelius, L. Serneels, H. Kvartsberg, B. De Strooper, K. Blennow, H. Zetterberg and F. Livesey (2017). Phenotypic Screening Identifies 
Modulators of Amyloid Precursor Protein Processing in Human Stem Cell Models of Alzheimer's Disease. Stem Cell Reports, 8(4), pp. 870-882.

Pen, A. and U.Jensen (2017). Current Status of Treating Neurodegenerative Disease with Induced Pluripotent Stem Cells. Acta Neurologica Scandinavica, 135(1), pp. 57-72.

Pistollato, F., S. Cavanaugh and P. Chandrasekera (2015). A Human-based Integrated Framework for Alzheimer's Disease research. Journal of Alzheimer's Disease, 47(4), pp. $857-868$.

Pistollato, F., E. Ohayon, A. Lam, G. Langley, T. Novak, D. Pamies, G. Perry, E. Trushina, R. Williams, A. Roher, T. Hartung, S. Harnad, N. Barnard, M. Morris, M. Lai, R. Merkley and P. Chandrasekera (2016b). Alzheimer Disease Research in the 21st Century: Past and Current Failures, New Perspectives and Funding Priorities. Oncotarget, 7 (26), pp. 38999-39016.

Mungenast, A., S. Siegert and L. Tsai (2016). Modeling Alzheimer's Disease with Human Induced Pluripotent Stem (iPS) Cells. Molecular and Cellular Neuroscience, 73, pp. 13-31.

Weiner, M., D. Veitch, P. Aisen, L. Beckett, N. Cairns, R. Green, D. Harvey, C. Jack, W. Jagust, J. Morris, R. Petersen, A. Saykin, L. Shaw, A. Toga, J. Trojanowski and Alzheimer's Disease Neuroimaging Initiative. (2017). Recent Publications from the Alzheimer's Disease Neuroimaging Initiative: Reviewing Progress Toward Improved AD Clinical Trials. Alzheimer's \& Dementia, 13 (4), pp. e1-e85. 